\title{
Systematic Model-Based Methodology for Substitution of Hazardous Chemicals
}

\author{
Jhamb, Spardha; Liang, Xiaodong; Gani, Rafiqul; Kontogeorgis, Georgios M.
}

Published in:

ACS Sustainable Chemistry \& Engineering

Link to article, DOI:

10.1021/acssuschemeng.8b06064

Publication date:

2019

Document Version

Peer reviewed version

Link back to DTU Orbit

Citation (APA):

Jhamb, S., Liang, X., Gani, R., \& Kontogeorgis, G. M. (2019). Systematic Model-Based Methodology for Substitution of Hazardous Chemicals. ACS Sustainable Chemistry \& Engineering, 7(8), 7652-7666.

https://doi.org/10.1021/acssuschemeng.8b06064

\section{General rights}

Copyright and moral rights for the publications made accessible in the public portal are retained by the authors and/or other copyright owners and it is a condition of accessing publications that users recognise and abide by the legal requirements associated with these rights.

- Users may download and print one copy of any publication from the public portal for the purpose of private study or research.

- You may not further distribute the material or use it for any profit-making activity or commercial gain

- You may freely distribute the URL identifying the publication in the public portal

If you believe that this document breaches copyright please contact us providing details, and we will remove access to the work immediately and investigate your claim. 


\title{
Article
}

Subscriber access provided by DTU Library

\author{
A Systematic Model-based Methodology \\ for Substitution of Hazardous Chemicals \\ Spardha Jhamb, Xiaodong Liang, Rafiqul Gani, and Georgios M. Kontogeorgis \\ ACS Sustainable Chem. Eng., Just Accepted Manuscript • DOI: 10.1021/ \\ acssuschemeng.8b06064 - Publication Date (Web): 04 Mar 2019
}

Downloaded from http://pubs.acs.org on March 11, 2019

\section{Just Accepted}

"Just Accepted" manuscripts have been peer-reviewed and accepted for publication. They are posted online prior to technical editing, formatting for publication and author proofing. The American Chemical Society provides "Just Accepted" as a service to the research community to expedite the dissemination of scientific material as soon as possible after acceptance. "Just Accepted" manuscripts appear in full in PDF format accompanied by an HTML abstract. "Just Accepted" manuscripts have been fully peer reviewed, but should not be considered the official version of record. They are citable by the Digital Object Identifier (DOI®). "Just Accepted" is an optional service offered to authors. Therefore, the "Just Accepted" Web site may not include all articles that will be published in the journal. After a manuscript is technically edited and formatted, it will be removed from the "Just Accepted" Web site and published as an ASAP article. Note that technical editing may introduce minor changes to the manuscript text and/or graphics which could affect content, and all legal disclaimers and ethical guidelines that apply to the journal pertain. ACS cannot be held responsible for errors or consequences arising from the use of information contained in these "Just Accepted" manuscripts. 


\title{
A Systematic Model-based Methodology for Substitution of Hazardous Chemicals
}

\author{
Spardha Jhamb ${ }^{a}$, Xiaodong Liang ${ }^{a}$, Rafiqul Gani ${ }^{b}$, Georgios M. Kontogeorgis ${ }^{a^{*}}$ \\ ${ }^{\text {a }}$ KT Consortium, Department of Chemical and Biochemical Engineering, \\ Technical University of Denmark, Building 229, Søltofts Plads 229, DK - 2800, Kgs. Lyngby, \\ Denmark. \\ ${ }^{\mathrm{b}}$ PSE for SPEED, Skyttemosen 6, DK - 3450 Allerød, Denmark \\ *Correspondence to Georgios M. Kontogeorgis, \\ KT Consortium, Department of Chemical and Biochemical Engineering, \\ Technical University of Denmark, Building 229, Søltofts Plads 229, DK - 2800, Kgs. Lyngby, \\ Denmark.
}

Email: gk@kt.dtu.dk; Telephone: +45 452528 59; Fax: +45 45882258 


\begin{abstract}
Driven by obligations to comply with the regulations and various public policies, substitution of chemicals with safer counterparts is now being widely practiced by industry. In this paper, the development of a systematic model-based methodology for chemical substitution, is described. The methodology considers different problem definitions depending on the objective for substitution. A general framework, which includes the algorithm steps of the methodology, corresponding data-flow, associated property models, databases and modeling tools for generating and evaluating the substitute candidates, is presented. The application of the developed methodology is highlighted through four case studies on substitution of 'chemicals of concern' used in chemical-based products or in processes and their operation. The alternative chemicals are found by matching the desired properties related to the physicochemical nature, function and performance of the chemical being substituted, while avoiding its undesired, environmental, health and safety-related properties.

The objective of developing this methodology for chemical substitution is to quickly and reliably identify the promising candidates through model-based techniques, check their economic feasibility and only then proceed to conduct experiments in order to verify their compatibility and applicability. In this way, the experimental resources are used only for verification rather than for an inefficient, trial-and-error and sometimes time-consuming and expensive search for substitute candidates.
\end{abstract}

KEYWORDS: Chemical Substitution, Model-based Methodology, Property Models, Tools, Alternative Chemicals, Environmental, health and safety 


\section{Introduction}

\section{Objective for Chemical Substitution}

Many hazardous chemicals are found in industrial processes, commodity products and consumer products. Both, humanity and environment are exposed to harmful properties of these chemicals, which have been shown to be detrimental to human health and have adverse effects on ecosystems like loss of biodiversity ${ }^{1-2}$. Therefore, different legislations framed by the regulatory bodies have restricted the use of hazardous chemicals (e.g. Restriction of Hazardous Substances Directive by the European Chemical Agency, $\mathrm{EChA}^{3}$ ). They have also provided various degrees of incentives to substitute such chemicals used in manufacturing processes, equipment operations and formulated products, with environmentally benign and safe alternatives (e.g. EU Chemical Agents Directive, EU Carcinogens and Mutagens Directive ${ }^{4}$ ). Moreover, reputed organizations have already realized the importance of worker health and safety benefits and have experienced increase in productivity as well as have saved money by simply reducing the use of hazardous chemicals and implementing safer alternatives (U.S. Occupational Health and Safety Administration ${ }^{5}$ ). Hence, besides the objective of protecting humans and the environment from the dangers of unsafe chemicals, the regulations imposing chemical substitution have also provided socio-economic benefits.

\section{State of the Art in Chemical Substitution}

Efforts by various organizations, universities and government bodies have resulted in the development of several frameworks and tools to identify and evaluate alternatives. The available tools can be broadly classified into two categories: tools that can be used to identify and assess the substitute candidates and databases that contain organized information but no mechanism for manipulation for users ${ }^{6}$. For instance, the Program for Assisting the Replacement of Industrial Solvents (PARIS) III tool developed by the US-EPA (United States Environmental Protection Agency) assists users in finding mixtures of solvents with specific properties that have reduced 
environmental impacts ${ }^{7}$ by performing a comparative analysis of the 'compound of concern' with known potential alternatives. On the other hand, the Toxicology Data Network (TOXNET) ${ }^{8}$, which is a comprehensive collection of databases managed by the National Institutes of Health (NIH), provides data and references for potentially hazardous chemicals. On entering a chemical ID or associated hazards into the search field, cross-references are made, and the results are returned from the following databases: Toxicology Literature Online (TOXLINE), Developmental and Reproductive Toxicology Database (DART), Carcinogenic Potency Database (CPDB), Genetic Toxicology Data Bank (GENE-TOX), Comparative Toxicogenomics Database (CTD), Chemical Carcinogenesis Research Information System (CCRIS) and International Toxicity Estimates for Risk (ITER). Such a platform only provides the user to check for a given set of properties of a chemical available in the database network.

Apart from governmental and academic institutions, there have been several voluntary initiatives of businesses and industry. For example, the 'Substitute It Now' (SIN) List' is a NGO List containing substances fulfilling EU's Registration, Evaluation and Authorization of Chemicals (REACH) regulation criteria of qualifying as 'Substances of Very High Concern' (SVHCs) ${ }^{9}$. To date, the SIN List consists of some 919 CAS numbers divided into 31 groups. In the SIN List database, for every substance, there is information on hazardous properties, EU regulatory status, producing companies and production volume. When applicable, it also links to substitution case stories. A tool, SINimilarity is available through the SIN List database and it can identify substances that are structurally similar to SIN List substances. SINimilarity includes a reference database of 500,000 substances that have been pre-registered under $\mathrm{REACH}^{10}$.

Using the developed tools, several successful and less than successful attempts in reducing the risks associated with hazardous chemicals have been made. GreenScreen ${ }^{\circledR}$ has enabled Hewlett-Packard (HP) to make use of PVC-free polymers in their electronics while Natural Resources Defense Council 

below. 
Table 1. Comprehensive Databases and Tools developed for Chemical Substitution

\begin{tabular}{|c|c|c|c|c|}
\hline Sr. No. & $\begin{array}{l}\text { Introduction } \\
\quad \text { Year }\end{array}$ & Developers & Database or Tool & Tool Capabilities \\
\hline \multicolumn{5}{|c|}{ Databases } \\
\hline 1 & 2000 & US-EPA & ECOTOX $^{13}$ & $\begin{array}{l}\text { Provides single chemical environmental toxicity data on aquatic life, } \\
\text { terrestrial plants, and wildlife }\end{array}$ \\
\hline 2 & 2005 & National Institutes of Health (NIH) & TOXNET $^{8}$ & $\begin{array}{l}\text { Resource for searching multiple databases on toxicology, hazardous } \\
\text { chemicals, environmental health, and toxic releases }\end{array}$ \\
\hline 3 & 2008 & $\begin{array}{l}\text { The International Chemical Secretariat } \\
\text { (ChemSec) }\end{array}$ & SIN List ${ }^{9}$ & $\begin{array}{l}\text { List of substances fulfilling REACH SVHC criteria; for every listed } \\
\text { substance, there is information on hazardous properties, EU regulatory } \\
\text { status, producing companies and production volume. When applicable, it } \\
\text { also links to substitution case stories. }\end{array}$ \\
\hline 4 & 2015 & Royal Society of Chemistry & ChemSpider ${ }^{14}$ & $\begin{array}{l}\text { Provides access to over } 59 \text { million chemical structures, properties, and } \\
\text { associated information }\end{array}$ \\
\hline 5 & 2015 & GreenBlue ${ }^{\circledR}$ & CleanGredients ${ }^{\circledR}{ }^{15}$ & $\begin{array}{l}\text { Provides a database of chemical ingredients used primarily to formulate } \\
\text { residential, institutional, industrial, and janitorial cleaning products that } \\
\text { have been pre-approved to meet the U.S. EPA's Safer Choice Standard }\end{array}$ \\
\hline 6 & 2015 & US-EPA Safer Choice Program & $\begin{array}{l}\text { Safer Chemical } \\
\text { Ingredients List (SCIL) }\end{array}$ & $\begin{array}{l}\text { Identifies intrinsic characteristics such as known human health hazards } \\
\text { associated with a chemical and prioritizes substances for alternatives } \\
\text { assessment based on attributes of interest }\end{array}$ \\
\hline 7 & 2018 & US-EPA and OSHA & $\begin{array}{l}\text { OSHA Occupational } \\
\text { Chemical Database }^{17}\end{array}$ & $\begin{array}{l}\text { Identifies physical properties, known human health hazards, exposure } \\
\text { guidelines, and emergency response information }\end{array}$ \\
\hline
\end{tabular}




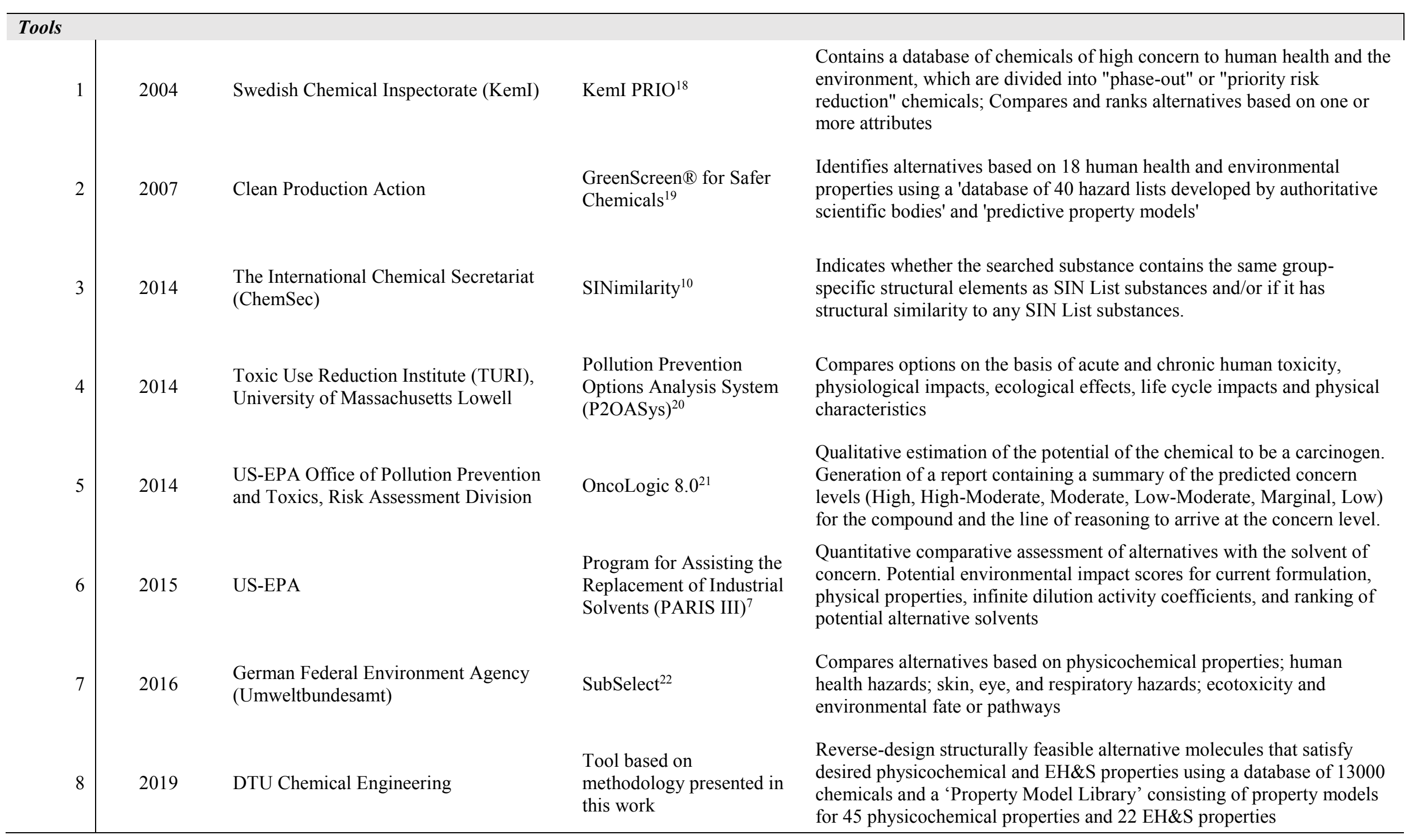




\section{Gaps and Limitations of Existing Methods and Tools}

Experimental data for the eco-(toxicological) properties is not always available for all chemicals. Moreover, when the data is available, the reliability of the data is questionable. One way to fill these data gaps is, to use relevant predictive models. Also, in many cases it is difficult for the user to interpret and use the available data. Therefore, it is important to have a guide that describes these properties qualitatively.

Although several alternatives assessment frameworks have been developed by both academia and regulatory agencies (for example, REACH Guidance on the Preparation of an Application for Authorization $^{23}$, Design for the Environment (DfE) ${ }^{24}$ by the US-EPA), a versatile methodology that can solve this problem in a systematic manner is required, so that a viable solution can be reached quickly by any user. The Chemical Alternatives Selection Framework by the National Research Council $^{25}$ is one such systematic framework with a clear step-wise procedure. However, like other frameworks, the 'identification of alternatives' step is carried out by first screening a list of known, potential alternatives for the desired performance using either experimental data or predictive property models followed by conducting time-consuming experimental procedures on the reduced candidate list to test for the Environmental, Health and Safety (EH\&S) properties. Therefore, the use of predictive property models and tools is restricted to property prediction and is not utilized for a rapid generation and design of reliable alternatives. Also, there are chemicals that show poor solubility in water or are unstable at high temperatures. For such chemicals it is difficult to perform experiments and assess their EH\&S properties ${ }^{26}$.

Considering these reasons, we have recognized the need for a model-based methodology for chemical substitution that could help enhance existing alternatives assessment frameworks. A substitution methodology, which can identify and generate promising substitute candidates through both, database-search and model-based techniques, check their economic feasibility and only then make 
use of experiments to verify and test their compatibility and applicability, has been developed in this work. Here, the generation of alternatives is carried out using a set of molecular building blocks as the starting point. All structurally feasible molecules are then screened to select those that satisfy the specified target property constraints (Generate and Test approach of CAMD $\left.{ }^{27}\right)$ using property models. This methodology has been used to identify viable and safer chemical alternatives in four casestudies. A detailed analysis of the results obtained has been presented.

\section{Chemical Substitution Methodology, Associated Property Models and Modeling Tools}

\section{Scope and Applicability of the Developed Methodology for Chemical Substitution}

The developed methodology can be used to solve a chemical substitution problem, wherein a 'single molecular chemical product' or 'a chemical from multicomponent liquid phase formulations or blends', which is an environmental hazard, a human-health hazard or both, needs to be substituted. These single molecular products, formulations and blends are useful either as consumer products, process solvents or working fluids in equipment. The versatility of this method lies in the fact that the products and processes being considered can belong to a variety of industrial sectors like automobiles, paints and surface coatings, cosmetics and personal care, agro-chemicals etc.

\section{A Generic Framework for Model-based Chemical Substitution}

A workflow diagram for the developed methodology for chemical substitution available through the framework, which incorporates model-based methods, databases and tools, is shown in Figure 1. This framework is targeted to researchers, engineers, chemists, environmental scientists, product formulators, that is, anybody who may need to study chemical-based products or processes that use or manufacture these products. The capability of a tool which can be developed based on this framework is mentioned in Table 1. 


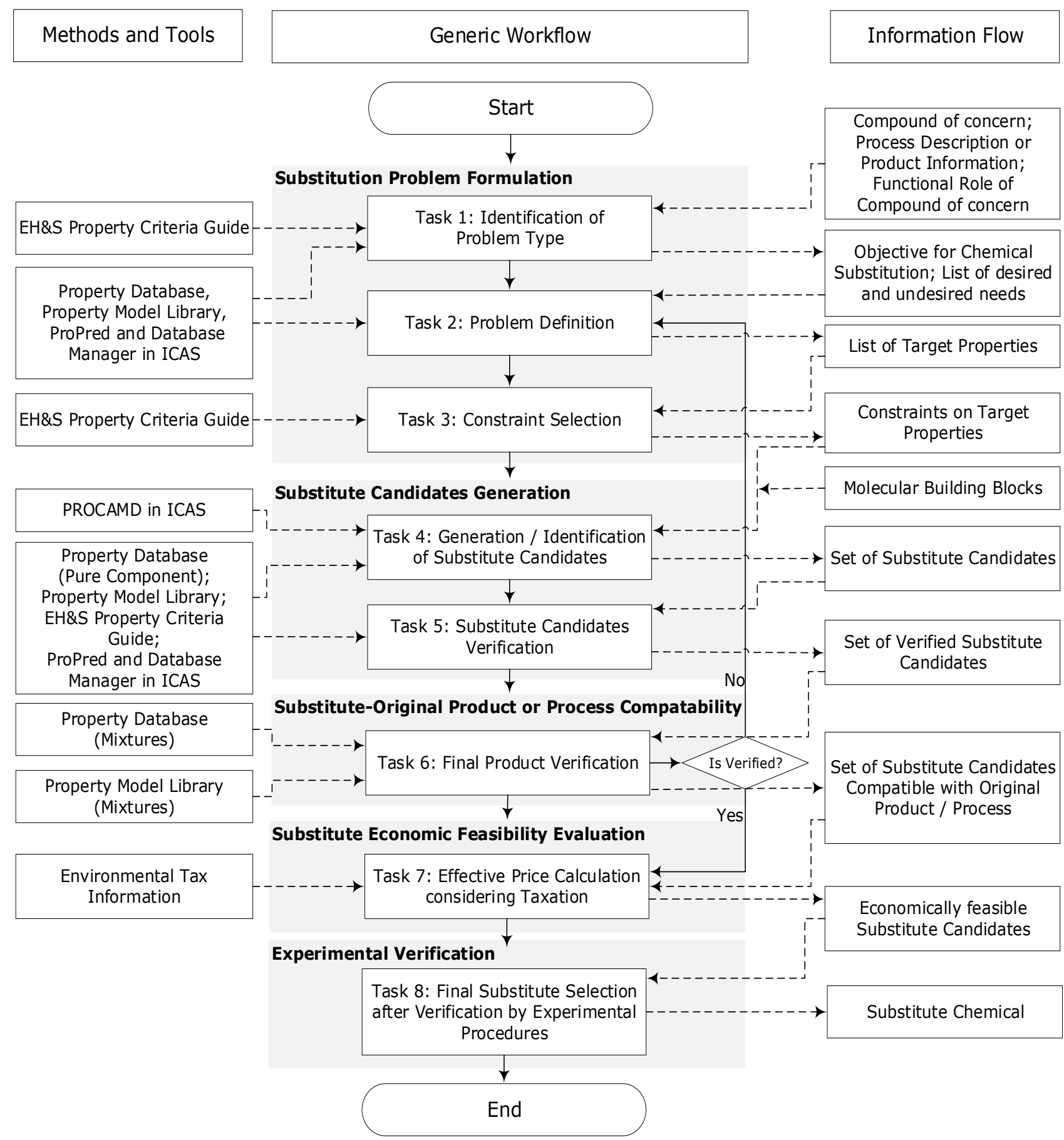

Figure 1. Workflow diagram for the chemical substitution methodology

\section{Components of Methodology Development}

In order to follow the sequence of tasks in the methodology, three methods and their associated tools have been developed or expanded. These are regarded as the components of methodology development, which are namely, 'Environmental, Health and Safety (EH\&S) Property Criteria 
Guide', 'Property Model Library' and 'Property Database'. It is essential that they are not only very comprehensively available so that a wide range of problems can be solved but are also flexible to allow for the addition of new models, data and criteria.

\section{Environmental, Health and Safety (EH\&S) Property Criteria Guide}

The EH\&S properties enable us to determine whether the 'compound of concern' is an environmental hazard or a human health hazard and categorize the compound in terms of the specific problem it can cause, if it is continued to be used. The criteria that aid in selecting the objective for substitution have been defined by making use of the 'substance classification and labelling' requirements under REACH regulations ${ }^{28}$ and the DfE Alternatives Assessment Program by US-EPA ${ }^{11}$. These criteria have been adapted to the property models available in the 'Property Model Library' (second component of methodology development) and a guide to select the 'objective for substitution' for a user of this methodology is prepared as shown in Figure 2.

For instance, benzene appears on the REACH Restricted Substance List and SIN List because it is classified as a CMR (carcinogenic, mutagenic and reprotoxic) substance. If a user of this methodology would like to find a substitute for benzene, he/she would first need to identify all the hazards associated with benzene and consequently the objective for substitution. By simply entering the name of the compound of concern i.e. benzene, in this case or its CAS number i.e. 71-43-2, all the values of the EH\&S properties for benzene from the 'Property Database' can be obtained. In case the experimental values of these properties are not available in this database, they can be predicted using the EH\&S property models available in the 'Property Model Library'. These property values are then required to be checked against the criteria shown in the last row for each section of the guide (the guide consists of two sections namely 'Environmental Hazard' and 'Human Health Hazard'). If one or more of these criteria are fulfilled then the specific objective corresponding to these criteria (available in row above the criteria), is selected. For benzene, the ratio of the biological oxygen 
demand for 5 days $\left(B_{5}\right)$ to the chemical oxygen demand $(C O D)$ is 0.38 and it is listed in the ' $\mathrm{CMR}$ Database'. Since, in addition to the CMR classification the $B O D_{5}$ to $C O D$ ratio is less than 0.5 , the objective for substituting this chemical is that it is 'carcinogenic, mutagenic, toxic for reproduction' and 'persistent in the environment'. Corresponding to the identified objective, the constraints on the values of relevant EH\&S properties are set during substitute identification, whereas all other EH\&S properties of substitute candidates are checked post substitute generation or identification.

Hence, this 'EH\&S Property Criteria Guide' is used in three steps of the developed methodology; to select the objective for substitution in Task 1, to guide in selecting the constraints on EH\&S properties in Task 3 and in verification of all EH\&S properties of the identified substitute candidates in Task 5. 


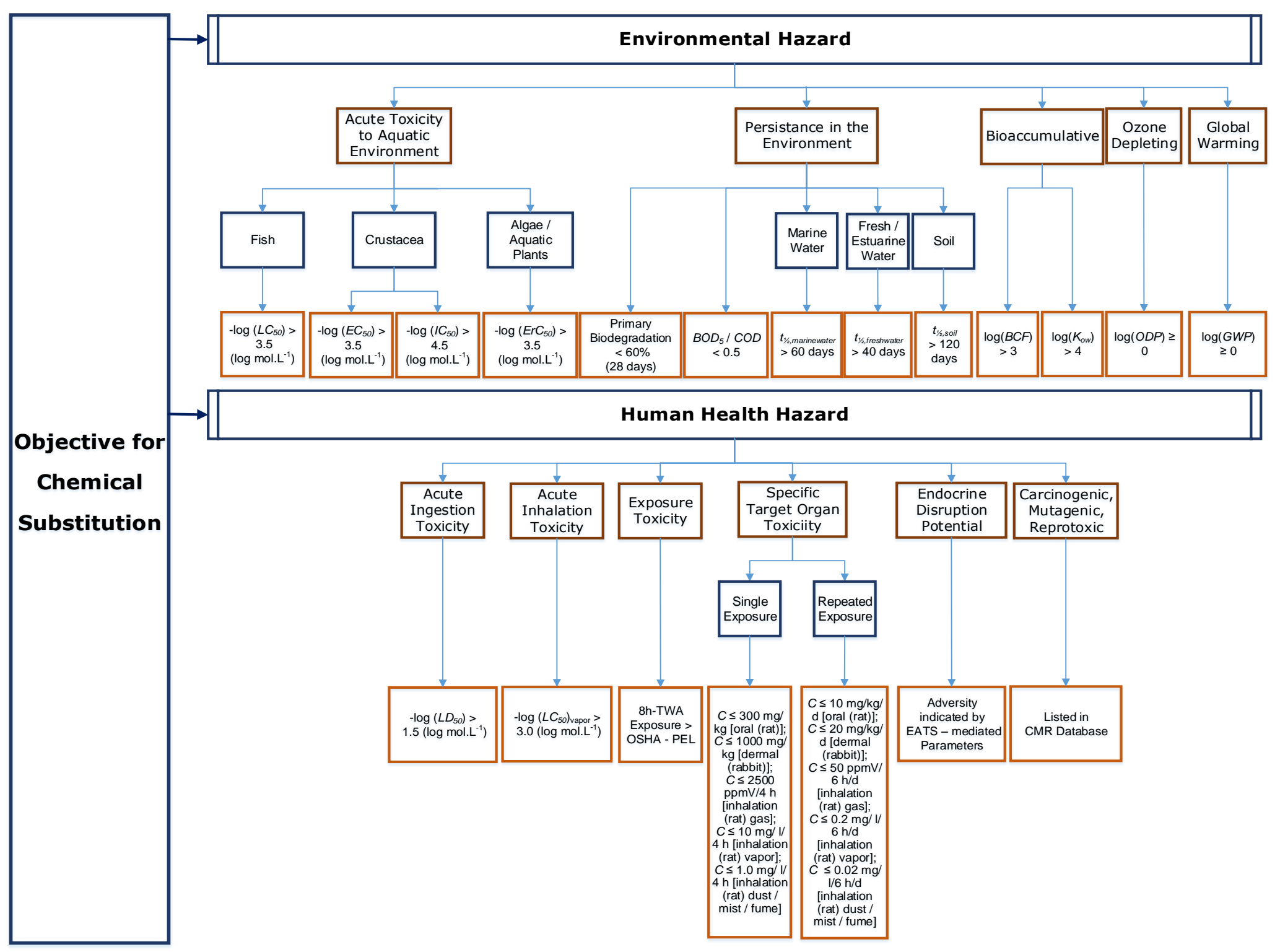

Figure 2. EH\&S Property Criteria Guide 


\section{Property Model Library}

The 'Property Model Library' (Figure 3) consists of pure component, mixture and product performance property models for a variety of organic compounds. The property models in this library have been developed during the previous works ${ }^{29-38}$ at DTU Chemical Engineering (KT Consortium).

The primary properties, which depend only on the molecular structure of the compounds, are predicted using Group Contribution (GC) models, for instance the critical properties $\left(T_{c}, P_{c}\right)$, physicochemical properties like melting point $\left(T_{m}\right)^{29-31}$ and EH\&S properties ${ }^{32}$.

The secondary properties can be predicted either using theoretical definition like critical compressibility factor $\left(Z_{c}\right)$ or using correlations of one or more primary properties. The thermodynamic models, specifically, the phase equilibria prediction models to determine the equilibrium compositions of a two-phase, binary or multicomponent mixture, are used in this work. The product performance models, to estimate the mixture properties, are classified according to the class of products i.e. blends of molecules ${ }^{23-24}$, homogeneous liquid phase formulations ${ }^{36}$, emulsions ${ }^{37}$ and devices ${ }^{38}$. This 'Property Model Library' is available via the ProPred tool in ICAS ${ }^{39}$. 
Figure 3. Property Model Library

\section{Property Database}

The property database available at DTU Chemical Engineering (KT-Consortium) contains data for 45 pure component properties of different types (primary, secondary and functional) and 9 mixture properties of more than 13,000 compounds classified into nine main categories according to molecular structure: normal fluid, polar associating, polar non-associating, multifunctional (with respect to groups), water, polymer, electrolyte, steroid and amino acids ${ }^{33}$. Data on $22 \mathrm{EH} \& \mathrm{~S}$ properties is also available ${ }^{32}$. The values of all these properties can be obtained by the user via the Database Manager Tool in ICAS ${ }^{39}$. Additionally, a separate database containing CMR substances and biodegradation-related properties has been compiled. 
However, currently no experimental data or predictive models for endocrine disruption, specific target organ toxicity and toxicity to aquatic plants are available in the 'Property Database' and 'Property Model Library' respectively.

\section{A Model-based Methodology}

A 'compound of concern', within the scope of this methodology, is a chemical appearing on the regulatory lists like the REACH 'Substances of Very High Concern' (SVHC) list and REACH 'Restricted Substances List' prepared by the EChA (Echa.europa.eu, 2007), any other regulatory list or organic pollutant list. Now, in order to find a substitute for this 'compound of concern' the user can follow the Tasks $1-8$ outlined in the workflow diagram of Figure 1. The data input required to be provided by the user is the chemical name or CAS Number of the 'compound of concern'. In the case of substitution from a product, the complete product information in terms of the constituents and their composition along with the product-use conditions are required to be provided by the user. Whereas, in the case of substitution of a chemical used in a process or its operation, the complete process description including process operating parameters are required to be provided. Also, the main functional role of this compound in the product or process must be specified. An elaboration of the eight tasks, in order to arrive at a substitute, is provided below.

Task 1. Identification of Problem Type: Firstly, the 'objective for substitution' using the 'EH\&S Property Criteria Guide' shown in Figure 2 is identified. This in-turn determines the type of substitution problem that is required to-be solved, i.e., whether the 'compound of concern' is problematic due to its toxicity to the aquatic environment, persistence in the environment, toxicity on ingestion or a combination of one or more hazards.

Task 2. Problem Definition: Next, the substitution problem is mathematically formulated. The properties which pertain to the physicochemical nature at the product-use or process operating 
conditions and the main function of the 'compound of concern' are classified as 'desired'. Besides, the properties to check for the performance of the substituted product mixture or compatibility with other chemicals used in a process are also identified and classified as 'desired'. While, the properties of the 'compound of concern' which pertain to environment, health and safety aspects are classified as 'undesired'.

Task 3. Constraint Selection: The target physicochemical and functional property constraints of the 'substitute to-be identified' are selected in such a way that their values are as close as possible to the 'desired' pure component and mixture properties of the 'compound of concern'. The target EH\&S property constraints, on the other hand, are set as far as possible from the 'undesired' properties of the 'compound of concern', such that they comply with the REACH regulations laid down by EChA and other environmental regulations by US-EPA available via the 'EH\&S Property Criteria Guide'.

\section{Task 4. Identification and Generation of Substitute Candidates}

4A. Database Search and Literature Review: The substitute candidates are identified by means of the 'database-search' technique using the 'Property Database' that includes measured values of physicochemical, performance and EH\&S target properties. Additionally, the alternatives that are currently being used as well as the alternatives that are found to be suitable by other research groups are identified via a literature review.

4B. Generation from Molecular Building Blocks: Next, the substitute candidates are generated by the Computer-Aided Molecular Design (CAMD) algorithm within the Pro-CAMD tool in ICAS ${ }^{39}$. This tool makes use of the property model library and target property constraints (on pure-component and mixture properties) together with the structural constraints to identify the alternatives using the molecular building blocks specified by the user. The description of the mathematical model used to formulate a CAMD problem is available in the Supporting Information. 
Task 5. Substitute Candidate Verification: In the case when it is chosen to generate substitute candidates by CAMD in Task 4B, if some of the property models have known uncertainties, then these properties can be checked at this stage (verification) using a property database or by using rigorous pure component property models. Besides, all the EH\&S properties, apart from the ones on which constraints are set in Task 3, are also checked here using either the 'Property Database' or 'Property Model Library' in order to avoid regrettable substitutions.

Task 6. Process or Product Compatibility Verification: After the list of verified substitute candidates is obtained, it is checked whether they fit in the original mixture or are compatible with the original process. In the case of a product, this can be done by first screening the candidates based on mixture properties calculated through linear mixing rules, then by rigorous thermodynamic or other mixture property models, and finally by using the 'Property Database'. Whereas, in the case of a chemical used in a process or equipment operation, the properties of the substitute candidate at the operating temperature and pressure conditions are tested using rigorous simulation tools or pilot-scale experimental data. If at this stage, the verification fails, then the problem formulation needs to be revised, that is, either some of the properties need to be compromised for other important ones or the constraints need to be relaxed and the tasks $2-6$ must be repeated.

Task 7. Economic Feasibility Evaluation of Substitute: Often potential alternative compounds that are environmentally friendly and safe for human health are priced higher than the 'compound of concern'. If only the basic economics related to substitution is to be checked, then only the prices of the substituted chemical and the substitute candidates are needed. The objective then would be to find the chemical that has the lower price, assuming all other conditions are unaltered. However, in the more detailed analysis, wherein the government bodies have implemented an environmental tax on polluting chemicals, the effective price of using the 'compound of concern' would increase. Apart 
from the tax, other economic considerations may also be considered. For example, additional costs for replacing a chemical as opposed to increased profit and acceptable environmental impact.

Task 8. Final Substitute Selection: Finally, the substitute is selected after all its properties have been checked through experimental procedures and its life cycle assessment has been performed.

It should be noted that the application range of the computer aided tool implementing the modelbased methodology depends on the application range of the property models available in the model library of the tool. However, if sufficient data can be found for the selected target property, the parameters of a required GC model can be estimated, or, a completely new model may be developed through the property modelling tool-box in Pro-CAPD ${ }^{40}$. This needs to be done before the application of the tool with the implemented model-based methodology.

\section{Case Studies Applying the Chemical Substitution Methodology}

Using the methodology described in the previous section, four case-studies on substituting hazardous chemicals, have been solved and elaborated below. The experimental verification (Task 8) has not been performed as the objective here is to only show the potential of the methodology to reach a set of reliable substitute candidates.

\section{Ethylene Glycol in an Engine Coolant}

Several consumer products used for the operation and maintenance of automobiles contain ethylene glycol (EG). EG is used as an anti-freezing agent in brake fluids, windshield washer fluids, engine coolants, automobile wax and polish etc. $45 \%$ (by volume) of a particular engine coolant, 'Prestone Extended Life 50-50 Ready to Use'41, is made up of EG. However, this chemical appears on the groundwater pollutant list of several US states. The high value of negative logarithm of $\mathrm{LD}_{50}$ suggests its acute toxicity to mammals ${ }^{42}$ and a low ratio of $\mathrm{BOD}_{5}$ to $\mathrm{COD}$ indicates its persistence in the environment (Task 1). Therefore, in order to find a substitute for EG, the desired and undesired 
properties of EG are identified and converted to target pure component and mixture properties of the substitute (Task 2) as shown in Table 2. The constraints on the desired properties like normal melting point, normal boiling point, heat of fusion etc., associated with the physicochemical nature, function and performance of the additive, are selected as close as possible to those of EG, while the $-\log \left(L D_{50}\right)$ and $\mathrm{BOD}_{5}$ to $C O D$ ratio should conform with the regulatory limits available through the 'EH\&S Property Criteria Guide'. For instance, since the heat of fusion for EG is $9 \mathrm{~kJ} \mathrm{~mol}^{-1}$, the substitute candidate should have a heat of fusion value in between $7 \mathrm{~kJ} \mathrm{~mol}^{-1}$ and $13 \mathrm{~kJ} \mathrm{~mol}^{-1}$ (Task 3 ).

Table 2. Needs, Target Properties and Constraints for Ethylene Glycol Substitution

\begin{tabular}{|c|c|c|}
\hline Need & Target Property & Target Property Constraints \\
\hline \multicolumn{3}{|c|}{ Pure component, physicochemical and functional properties of substitute } \\
\hline $\begin{array}{l}\text { Heat removal without much rise } \\
\text { in its own temperature }\end{array}$ & Heat Capacity $\left(C_{p, 298 K}\right)$ & $75 \mathrm{~J} \mathrm{~mol}^{-1} \mathrm{~K}^{-1}<C_{p, 298 K}<300 \mathrm{~J} \mathrm{~mol}^{-1} \mathrm{~K}^{-1}$ \\
\hline Good heat transfer medium & Thermal Conductivity $\left(k_{300 K}\right)$ & $k_{300 K}>0.15 \mathrm{~W} \mathrm{~m}^{-1} \mathrm{~K}^{-1}$ \\
\hline Not freeze in cold climates & Heat of fusion $\left(\Delta H_{f u s}\right)$ & $7 \mathrm{~kJ} \mathrm{~mol}^{-1}<\Delta H_{\text {fus }}<13 \mathrm{~kJ} \mathrm{~mol}^{-1}$ \\
\hline Liquid phase & $\begin{array}{l}\text { Normal Melting Point }(N M P), \\
\text { Normal Boiling point }(N B P)\end{array}$ & $\begin{array}{c}203.2 \mathrm{~K}<N M P<293.2 \mathrm{~K}, \\
400 \mathrm{~K}<N B P<570 \mathrm{~K}\end{array}$ \\
\hline \multicolumn{3}{|c|}{ Pure component EH\&S properties of substitute } \\
\hline Non-toxic to mammals & Lethal Dose $\left(L D_{50}\right)$ & $-\log L D_{50}<1.5 \log \left(\mathrm{mol} \mathrm{kg}^{-1}\right)$ \\
\hline Biodegradable & $\begin{array}{l}\text { Ratio of Biochemical Oxygen } \\
\text { Demand for } 5 \text { days to Chemical } \\
\text { Oxygen Demand }\left(B O D_{5} / C O D\right)\end{array}$ & $B O D_{5} / C O D>0.5$ \\
\hline \multicolumn{3}{|c|}{ Performance properties of substituted mixture } \\
\hline $\begin{array}{l}\text { Not freeze in cold climates } \\
(1: 1 \text { mixture }(v / v) \text { of } \\
\text { substitute and water })\end{array}$ & $\begin{array}{l}\text { Freezing point depression } \\
\qquad(F P D)\end{array}$ & $5 \mathrm{~K}<F P D<25 \mathrm{~K}$ \\
\hline $\begin{array}{c}\text { Miscibility with other } \\
\text { constituents in original mixture }\end{array}$ & $\begin{array}{l}\text { Gibbs energy of mixing }\left(\Delta G_{m i x}\right) \text {, } \\
\text { Solubility Parameter }\left(\delta_{H i l d, 298 K}\right)\end{array}$ & $\begin{array}{c}\Delta G_{m i x} / R T<0, \\
25 \mathrm{MPa}^{1 / 2}<\delta_{H i l d, 298 K}<35 \mathrm{MPa}^{1 / 2}\end{array}$ \\
\hline
\end{tabular}

Since GC models ${ }^{29}$ for the prediction of the pure component properties (physicochemical, functional and EH\&S) listed in Table 2 and UNIFAC activity coefficient model for checking the miscibility with other constituents of the original product (3\% diethylene glycol, $1 \%$ propanol, $1 \%$ polypropylene glycol, $50 \%$ water by volume) are available in the property model library, CAMD is used to generate substitute candidates with the tool, Pro-CAMD. To have a comparable alternative to EG, the structural constraints are specified by selecting the building blocks of alcohols and ketones. 
As a result of this step, four substitute candidates are generated namely 1,2-propylene glycol (PG), 1,2-butanediol and its two isomers (Task 4B). The EH\&S properties, besides $L D_{50}$, are estimated for all the four candidates (Task 5) in order to check if they meet other regulatory limits. Although all EH\&S properties of 2-methyl-1,3-propanediol are below the regulatory limit, it is more toxic and bioaccumulative compared to $\mathrm{EG}$ as seen from the $-\log \left(\mathrm{LC}_{50}\right)_{\mathrm{FM}},-\log \left(\mathrm{LC}_{50}\right)_{\mathrm{DM}}$ and $\mathrm{BCF}$ values available in the Supporting Information.

The remaining three generated candidates are further evaluated for the performance properties (besides miscibility with other original constituents), that characterize the compatibility of the substitute with the original mixture (Task 6). In this case-study, the freezing point depression (FPD) of a mixture substituted with each of these three candidates is required to be checked. To facilitate this check, it is assumed that the substituted mixture is a 1:1 mixture (v/v) of substitute and water. All three substituted mixtures satisfy the FPD target property constraints. But the mixture with (PG) gives the maximum freezing point depression $(F P D)$ using the original UNIFAC activity coefficient model (shown in Figure 4). Besides, it also has the lowest toxicity to mammals (quantified by a $-\log L D_{50}$ value of $\left.0.58 \log \left(\mathrm{mol} . \mathrm{kg}^{-1}\right)\right)$ among these screened candidates. 


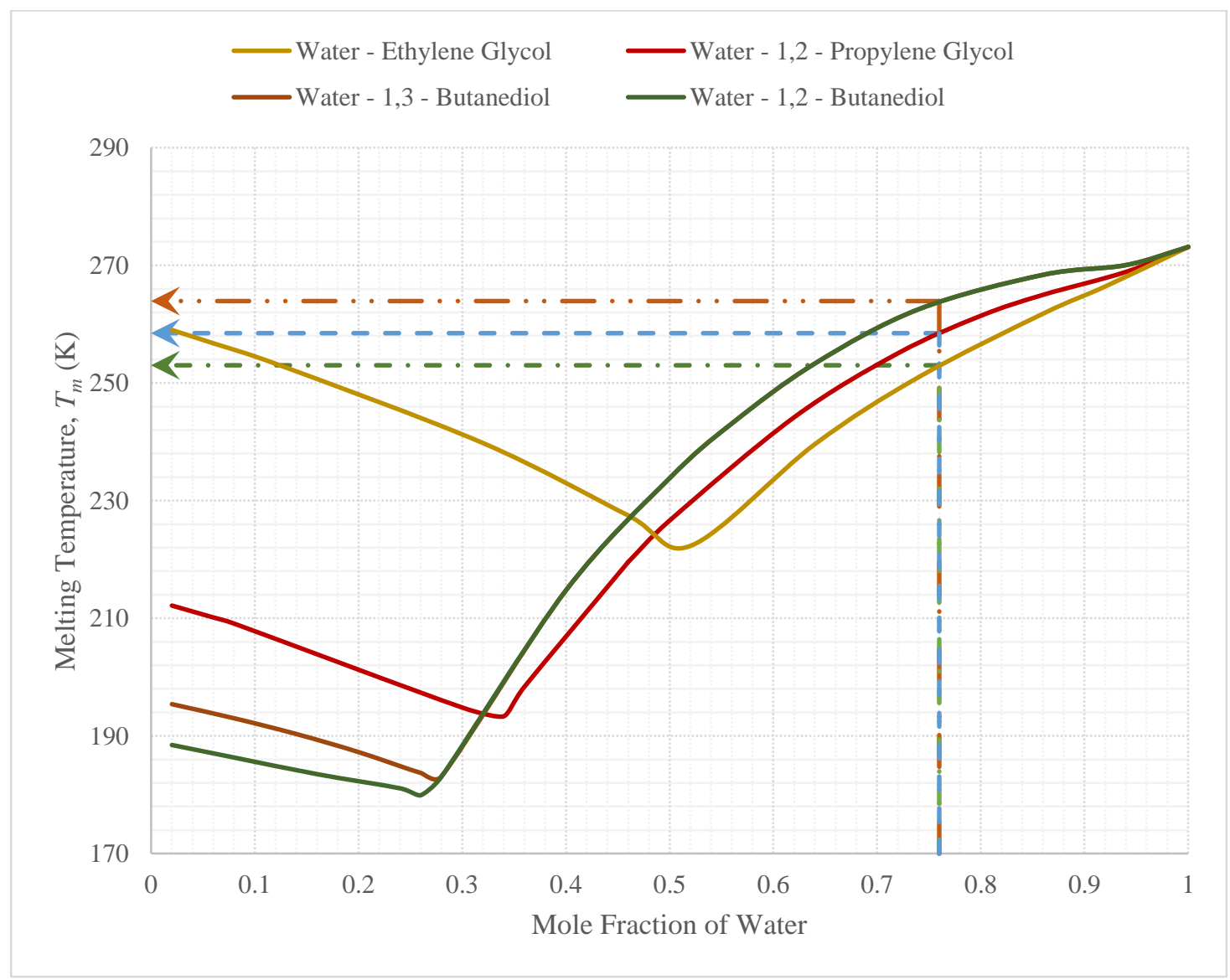

Figure 4. SLE curve to calculate Freezing Point Depression of Substituted Mixtures using UNIFAC Activity Coefficient Model and its comparison with the original mixture containing EG and Water

Therefore, if the same volume of EG is desired to be replaced by an equal amount of PG, then a freezing point depression of $12.5 \mathrm{~K}$ can be obtained. But if the freezing point depression $(20 \mathrm{~K})$ given by a 1:1 mixture of water and EG (or $x=0.76$ water) is required in the substituted product, then higher amounts of the substitute should be used. The amounts of these three substitute candidates required to prepare the alternative engine coolant formulation are shown in Table 3.

Table 3. Mole fraction of substitutes of EG to achieve a FPD of $20 \mathrm{~K}$

\begin{tabular}{|l|l|c|c|}
\hline Substitute of EG & CAS & Molecular Weight (g/mol) & Mole Fraction, $\boldsymbol{x}$ \\
\hline 1,2-propylene glycol & $57-55-6$ & 76.09 & 0.30 \\
\hline 1,2-butanediol & $504-63-2$ & 90.12 & 0.36 \\
\hline 1,3-butanediol & $107-88-0$ & & \\
\hline
\end{tabular}


In conclusion, three viable substitutes to EG have been identified. However, 1,2-propylene glycol gives the maximum freezing point depression, which is the most important performance property characterizing the role of the substitute (anti-freezing agent), while it also has the lowest toxicity to mammals and is readily biodegradable (Table 4). 
Table 4. Comparison of all properties of the viable substitutes with EG

\begin{tabular}{|c|c|c|c|c|c|c|c|c|c|c|c|c|}
\hline & Compound & $\begin{array}{l}\delta_{\text {Hild }, 298 K} \\
\left(\mathrm{MPa}^{1 / 2}\right)\end{array} \mid$ & $\begin{array}{c}k \\
\left(\mathbf{W m}^{-1} K^{-1}\right)\end{array}$ & $\begin{array}{c}\rho \\
(\mathrm{g} / \mathrm{cc})\end{array}$ & $\begin{array}{c}\text { NMP } \\
(\mathbf{K})\end{array}$ & $\begin{array}{r}N B P \\
(\mathbf{K})\end{array}$ & $\left(\begin{array}{c}C_{p} \\
\left(\mathrm{~J} \mathrm{~mol}^{-1} \mathrm{~K}^{-1}\right)\end{array}\right.$ & $\begin{array}{c}\Delta H_{f u s} \\
(\mathrm{~kJ} / \mathrm{mol})\end{array}$ & $\begin{array}{c}-\log \left(L D_{50}\right) \\
\left(\log \mathrm{mol} \mathrm{kg} \mathrm{kg}^{-1}\right)\end{array}$ & BOD $_{5} /$ COD & $\begin{array}{r}\text { FPD } \\
(\mathbf{K})\end{array}$ & $\begin{array}{c}\text { Miscibility with other } \\
\text { constituents in original } \\
\text { mixture } \\
\end{array}$ \\
\hline $\begin{array}{l}\text { Original } \\
\text { Compound }\end{array}$ & Ethylene glycol & 33.70 & 0.258 & 1.11 & 260.20 & 470.80 & 149.80 & 9.96 & 1.52 & 0.38 & 20.2 & Miscible \\
\hline \multirow{2}{*}{$\begin{array}{l}\text { Viable } \\
\text { Substitutes }\end{array}$} & $\begin{array}{l}\text { 1,2-propylene } \\
\text { glycol }\end{array}$ & 29.74 & 0.174 & 1.06 & 217.89 & 432.65 & 237.79 & 10.86 & 0.58 & 0.63 & 12.5 & Miscible \\
\hline & 1,2-butanediol & 27.79 & 0.166 & 1.02 & 228.59 & 454.17 & 269.18 & 12.84 & 0.75 & 0.56 & 5.02 & Miscible \\
\hline
\end{tabular}


Due to higher prices of the three substitute candidates, it may not be an economically feasible option to make use of these chemicals (Task 7). However, detailed economic analysis considering the reduced environmental impact must be conducted.

\section{Methylene Chloride in a Paint and Epoxy Remover}

More than $60 \%$ of the composition of several paint and epoxy removers as well as varnish thinners contain methylene chloride. For instance, the 'Jasco® Premium Paint and Epoxy Remover' is made up of $80 \%$ methylene chloride, $15-20 \%$ methanol and less than $5 \%$ of petroleum distillates ${ }^{41}$. (Methylene chloride is the principle active ingredient in this paint and epoxy remover). However, methylene chloride is listed on the REACH 'Restricted Substances List' as it is a Volatile Organic Compound (VOC) with a high vapor pressure of 0.58 bar and high toxicity to humans on vapor inhalation. In a study in Denmark ${ }^{43}$, it was reported that, concentrations of methylene chloride in the breathing zone was found to be from $210 \mathrm{ppm}\left(741 \mathrm{mg} / \mathrm{m}^{3}\right)$ to $2025 \mathrm{ppm}\left(7148 \mathrm{mg} / \mathrm{m}^{3}\right)$ when liquid paint strippers were used indoors under general ventilation conditions. This value is considerably higher than the Permissible Exposure Limit (PEL) of 500 ppm (8h-TWA) established by the OSHA and 100 ppm (8h-TWA) established in most EU countries (OECD, 1994). Therefore, methylene chloride is required to be substituted due to its acute inhalation toxicity (Task 1). Apart from consumers, formulators are also exposed to the vapor inhalation during mixing/blending operations and hence in the US, the ban of methylene chloride-containing paint strippers has also been a subject of discussion recently ${ }^{26-27}$.

To identify a substitute for methylene chloride using CAMD, the needs are first translated to target pure component and mixture properties of the substitute candidate to-be-identified (Task 2). The target property constraints on all the properties (except Hansen Solubility Parameters) are supplied in the Pro-CAMD tool as given in Table 5 (Task 3). As a result of this step, nine substitute candidates 
are generated (Task 4B). These are listed in Table 6. The properties of the substitute candidates were verified using the 'Property Database' (Task 5).

Additionally, to check if the substitute together with the other ingredients of the Jasco® stripper would give a similar performance as that of the original product, it has been assumed that the original product is a 20:80 \% (v/v) mixture of methanol and methylene chloride. The substituted mixture, where the volume of methylene chloride in the original product is replaced with an equal volume of substitute candidate, should be able to dissolve the epoxy resins. In this case-study, the epoxy resin considered is a polyester-based resin with a radius of solubility $=9 \mathrm{MPa}^{1 / 2}$ and Hansen Solubility Parameters, $\delta_{d l}=20 \mathrm{MPa}^{1 / 2}, \delta_{p l}=10 \mathrm{MPa}^{1 / 2}$ and $\delta_{h l}=8 \mathrm{MPa}^{1 / 246}$. Consequently, the generated candidates can be considered as viable substitutes only if their mixture with methanol can satisfy the rule of thumb for polymer-solvent solubility shown in Eq.1 (Task 6).

$R_{a}=\sqrt{4\left(\delta_{d 1}-\delta_{d 2}\right)^{2}+\left(\delta_{p 1}-\delta_{p 2}\right)^{2}+\left(\delta_{h 1}-\delta_{h 2}\right)^{2}} \leq R_{\text {epoxyResin }}$

Table 5. Needs, Target Properties and Constraints for Methylene Chloride Substitution

\begin{tabular}{|c|c|c|}
\hline Need & Target Property & Target Property Constraints \\
\hline \multicolumn{3}{|c|}{ Pure component, physicochemical properties of substitute } \\
\hline Liquid phase & $\begin{array}{c}\text { Normal Melting Point }(N M P) \text {, } \\
\text { Normal Boiling point }(N B P)\end{array}$ & $\begin{array}{c}N M P<253.2 \mathrm{~K} \\
300 \mathrm{~K}<N B P<400 \mathrm{~K}\end{array}$ \\
\hline Low volatility & Vapor pressure $(V P)$ & $\mathrm{VP}<0.58$ bar \\
\hline Low flammability & Flash Point $(F P)$ & $F P>240 K$ \\
\hline \multicolumn{3}{|c|}{ Pure component, EH\&S properties of substitute } \\
\hline Non-toxic in vapor phase & Vapor toxicity $\left(L C_{50, v a p o r}\right)$ & $-\log L C_{50, \text { vapor }}<3 \log \left(\mathrm{mol} \mathrm{m}^{-3}\right)$ \\
\hline \multicolumn{3}{|c|}{ Performance properties of substituted mixture } \\
\hline $\begin{array}{c}\text { Miscibility in original mixture } \\
\text { (miscible with higher alkanes } \\
\left(\mathrm{C}_{14}-\mathrm{C}_{15}\right) \text { and lower alcohols, } \\
\text { specifically methanol) }\end{array}$ & $\begin{array}{c}\text { Gibbs energy of mixing }\left(\Delta G_{m i x}\right) \text {, } \\
\text { Solubility Parameter }\left(\delta_{H i l d, 298 \mathrm{~K}}\right)\end{array}$ & $\begin{array}{c}\Delta G_{m i x} / R T<0 \\
18 \mathrm{MPa}^{1 / 2}<\delta_{H i l d, 298 K}<21 \mathrm{MPa}^{1 / 2}\end{array}$ \\
\hline $\begin{array}{l}\text { Ability to dissolve epoxy resin } \\
(20: 80(v / v) \text { mixture of } \\
\text { methanol and substitute })\end{array}$ & $\begin{array}{l}\text { Hansen solubility parameters } \\
\qquad\left(\delta_{d 2}, \delta_{p 2}, \delta_{h 2}\right)\end{array}$ & $\begin{array}{c}\sqrt{4\left(20-\delta_{d 2}\right)^{2}+}\left(10-\delta_{p 2}\right)^{2}+\left(8-\delta_{h 2}\right)^{2} \\
\leq 9\end{array}$ \\
\hline
\end{tabular}


Out of the nine candidates, only the 20:80 (v/v) mixture of methanol and 2 - propanone could dissolve the polyester resin as this mixture has a solubility parameter distance, $R_{a}$ of $8.89 \mathrm{MPa}^{1 / 2}$ (Table 6 ).

Besides, the Danish EPA has imposed a tax of approximately $€ 5$ per $\mathrm{kg}$ of methylene chloride on its $\mathrm{use}^{47}$, resulting in the rise of its effective price from $€ 0.82$ per $\mathrm{kg}^{48}$ to $€ 5.82$ per $\mathrm{kg}$. Since, the price for 2 - propanone is $€ 0.96$ per $\mathrm{kg}^{48}$, this compound is not only a safe and effective substitute to methylene chloride (Table 7) but also an inexpensive solution when government regulations are in place (Task 7). 
Table 6. Further evaluation of CAMD generated candidates to check substituted-product performance

\begin{tabular}{|c|c|c|c|c|c|c|c|c|}
\hline & & \multicolumn{3}{|c|}{ Pure Component Solubility Parameters } & \multicolumn{3}{|c|}{ Solubility Parameters of a 4:1 v/v mixture with methanol } & \multirow{2}{*}{$\begin{array}{c}\text { Performance } \\
\text { properties of a } \\
\text { 4:1 v/v mixture } \\
\text { with methanol } \\
\text { Solubility } \\
\text { Parameter } \\
\text { Distance, } R_{a} \\
\left(\mathrm{MPa}^{1 / 2}\right)\end{array}$} \\
\hline & & $\begin{array}{c}\text { Hansen } \mathrm{D} \text {, sol } \\
\left(\mathrm{MPa}^{1 / 2}\right)\end{array}$ & $\begin{array}{l}\text { Hansen } \mathrm{P} \text {, sol } \\
\left(\mathrm{MPa}^{1 / 2}\right)\end{array}$ & $\begin{array}{l}\text { Hansen } \mathrm{H} \text {, sol } \\
\left(\mathrm{MPa}^{1 / 2}\right)\end{array}$ & $\begin{array}{l}\text { Hansen D, sol } \\
\delta_{d 2}\left(\mathrm{MPa}^{1 / 2}\right)\end{array}$ & $\begin{array}{l}\text { Hansen } \mathrm{P}, \text { sol } \\
\delta_{p 2}\left(\mathrm{MPa}^{1 / 2}\right)\end{array}$ & $\begin{array}{c}\text { Hansen } \mathrm{H} \text {, sol, } \\
\delta_{h 2}\left(\mathrm{MPa}^{1 / 2}\right)\end{array}$ & \\
\hline $\begin{array}{l}\text { Original } \\
\text { Mixture }\end{array}$ & $\begin{array}{l}\text { Methanol } \\
\text { Methylene chloride }\end{array}$ & $\begin{array}{l}15.59 \\
16.84 \\
\end{array}$ & $\begin{array}{l}6.96 \\
7.44 \\
\end{array}$ & $\begin{array}{r}14.01 \\
4.02 \\
\end{array}$ & 16.59 & 7.34 & 6.02 & 7.58 \\
\hline $\begin{array}{l}\text { CAMD } \\
\text { Generated } \\
\text { Substitute } \\
\text { Candidates }\end{array}$ & $\begin{array}{l}\text { Methyl Acetate } \\
\text { 2-Propanone } \\
\text { Ethyl Acetate } \\
\text { Methyl Ethyl Ketone } \\
\text { 3-Pentanone } \\
\text { 2-Pentanone } \\
\text { 2,2-dimethyl 1-propanol } \\
\text { 2-methyl 1-butanol } \\
\text { 3-pentanol }\end{array}$ & $\begin{array}{l}15.59 \\
\mathbf{1 5 . 7 3} \\
15.59 \\
15.72 \\
15.69 \\
15.72 \\
15.31 \\
15.50 \\
15.50\end{array}$ & $\begin{array}{l}4.85 \\
\mathbf{8 . 0 5} \\
4.70 \\
7.13 \\
4.61 \\
6.98 \\
6.45 \\
6.29 \\
6.29\end{array}$ & $\begin{array}{r}7.22 \\
\mathbf{5 . 6 5} \\
7.01 \\
5.09 \\
4.13 \\
4.87 \\
14.1 \\
13.73 \\
13.73\end{array}$ & $\begin{array}{l}15.59 \\
\mathbf{1 5 . 7 0} \\
15.59 \\
15.69 \\
15.67 \\
15.69 \\
15.37 \\
15.52 \\
15.52\end{array}$ & $\begin{array}{l}5.27 \\
7.83 \\
5.15 \\
7.10 \\
5.08 \\
6.98 \\
6.55 \\
6.42 \\
6.42 \\
\end{array}$ & $\begin{array}{r}8.58 \\
7.32 \\
8.41 \\
6.87 \\
6.11 \\
6.70 \\
14.08 \\
13.79 \\
13.79\end{array}$ & $\begin{array}{r}10.02 \\
\mathbf{8 . 8 9} \\
10.07 \\
9.16 \\
10.14 \\
9.22 \\
11.61 \\
11.25 \\
11.25\end{array}$ \\
\hline
\end{tabular}

Table 7. Comparison of all properties of the viable substitute with Methylene Chloride

\begin{tabular}{|c|c|c|c|c|c|c|c|c|c|c|}
\hline & Compound & $\begin{array}{l}\delta_{\text {Hild,298K }} \\
\left(\mathrm{MPa}^{1 / 2}\right)\end{array}$ & $\begin{array}{c}N M P \\
(\mathbf{K})\end{array}$ & $\begin{array}{c}N B P \\
(\mathbf{K})\end{array}$ & $\begin{array}{l}F P \\
(\mathbf{K})\end{array}$ & $\begin{array}{c}\mathrm{VP} \\
\text { (bar) }\end{array}$ & $\begin{array}{l}-\log L C_{50, v a p o r} \\
\left(\log \mathrm{mol} \mathrm{m}^{-3}\right)\end{array}$ & $\begin{array}{l}\text { Miscibility with } \\
\text { original mixture }\end{array}$ & $\begin{array}{c}R_{a} \text { when mixed with methanol } \\
\text { in a ratio of } 4: 1 \mathrm{v} / \mathrm{v}\end{array}$ & $\begin{array}{l}\text { Price } \\
(\epsilon / k g)\end{array}$ \\
\hline $\begin{array}{l}\text { Original } \\
\text { Compound }\end{array}$ & Methylene Chloride & 18.70 & 176.43 & 312.93 & 260.05 & 0.580 & 3.19 & Miscible & 7.58 & 5.82 \\
\hline $\begin{array}{l}\text { Viable } \\
\text { Substitute }\end{array}$ & 2 - propanone & 19.16 & 171.62 & 305.37 & 244.42 & 0.441 & 0.85 & Miscible & 8.89 & 0.96 \\
\hline
\end{tabular}




\section{Cetrimonium Bromide in a Hair Conditioner}

Cetrimonium bromide is a conventional mono-quaternary ammonium cationic surfactant, used in the hair conditioner, 'Rejuvenol Keratin after Treatment Conditioner' ${ }^{41}$. However, it is persistent in the environment and toxic to freshwater crustaceans ${ }^{49}$ (Task 1). In order to find a substitute for this surfactant, its desired surface-active and physicochemical properties and the undesired environmental properties are identified (Task 2). Constraints are set on the target property values of the 'substitute to-be identified', as given in Table 8 (Task 3).

Table 8. Needs, Target Properties and Constraints for Cetrimonium Bromide Substitution

\begin{tabular}{|c|c|c|}
\hline Need & Target Property & Target Property Constraints \\
\hline \multicolumn{3}{|c|}{ Pure component, physicochemical and surface-active properties of substitute } \\
\hline $\begin{array}{l}\text { Ability to form micelles / } \\
\text { Solubilize dirt and oils }\end{array}$ & Critical Micelle Concentration $(C M C)$ & $C M C<0.02 \mathrm{~mol} \mathrm{~L}^{-1}$ \\
\hline Ability to lower surface tension & Surface Tension at CMC $\left(\sigma_{C M C}\right)$ & $\sigma_{C M C}<40 \mathrm{mN} \mathrm{m}^{-1}$ \\
\hline Soluble in Water & Water solubility $\left(\log W_{s}\right)$ & $\log W_{s}>1.5 \log \left(\mathrm{mg} \mathrm{L}^{-1}\right)$ \\
\hline \multicolumn{3}{|c|}{ Pure component, EH\&S properties of substitute } \\
\hline Non-toxic to aquatic environment & Immobilization Concentration $\left(I C_{50}\right)$ & $-\log I C_{50}<4.5 \log \left(\mathrm{mol} \mathrm{m}^{-3}\right)$ \\
\hline Readily biodegradable & $\%$ Primary Biodegradation & $60 \%$ biodegradation in 28 days \\
\hline
\end{tabular}

The constraints on the physicochemical and surface-active properties are kept as close as possible to those of cetrimonium bromide. While, the constraints on EH\&S properties are chosen such that they satisfy the 'Safer Choice Criteria for Surfactants' established by US-EPA ${ }^{50}$ (also available in the 'EH\&S Property Criteria Guide').

An acceptable value of primary biodegradation is when $60 \%$ of the chemical mineralizes into degradation products which are not of concern in a period less than or equal to 28 days $^{32-33}$. Besides, the toxicity to aquatic environment is quantified using the immobilization concentration, $I C_{50}$. Here, $I C_{50}$ is the concentration value that causes immobilization in $50 \%$ of the Daphnia magna (fresh-water crustacean) after $24 \mathrm{~h}$ exposure ${ }^{52}$.

Surfactants with building blocks of natural compounds that are readily biodegradable like amino acids, are more likely to qualify as safer surfactants. Considering this fact, two amino acid-based 
surfactants ${ }^{53}$ are found to be viable substitutes by means of 'database search and literature review' (Task 4A). They have a biodegradation rate of greater than $60 \%$ and low toxicity to the aquatic environment. A comparison of the properties of the two identified substitutes with cetrimonium bromide is given in Table 9.

Table 9. Comparison of all properties of viable substitutes with Cetrimonium Bromide

\begin{tabular}{l|c|c|c|c|c|c}
\hline & Compound & $\begin{array}{c}\mathbf{C M C} \\
\left(\mathrm{mol} \mathrm{L}^{-1}\right)\end{array}$ & $\begin{array}{c}\boldsymbol{\sigma}_{\mathbf{C M C}} \\
\left(\mathrm{mN} \mathrm{m}^{-1}\right)\end{array}$ & $\begin{array}{c}\log \mathbf{W}_{\mathbf{s}} \\
\log \left(\mathrm{mg} \mathrm{L}^{-1}\right)\end{array}$ & $\begin{array}{c}-\log \mathbf{I C}_{\mathbf{5 0}} \\
\log \left(\mathrm{mol} \mathrm{m}^{-3}\right)\end{array}$ & $\begin{array}{c}\text { Primary } \\
\text { Biodegradation } \\
(\%)\end{array}$ \\
\hline $\begin{array}{l}\text { Original } \\
\text { Compound }\end{array}$ & Cetrimonium Bromide & 0.0009 & 38.0 & 4.56 & 6.88 & 44 \\
\hline \multirow{2}{*}{$\begin{array}{l}\text { Viable } \\
\text { Substitutes }\end{array}$} & $\begin{array}{c}\text { CAM }\left(\mathrm{N}_{\alpha} \text {-acyl-arginine }\right. \\
\left.\text { methyl ester, } n=8^{*}\right)\end{array}$ & 0.0160 & 40.0 & 1.53 & 4.11 & 95 \\
\cline { 2 - 7 } & $\begin{array}{c}\text { LKM }\left(\mathrm{N}_{\varepsilon} \text {-acyl lysine }\right. \\
\left.\text { methyl ester, } n=10^{*}\right)\end{array}$ & 0.0055 & 31.0 & 2.16 & 4.40 & 90 \\
\hline
\end{tabular}

${ }^{*}$ The surfactant is the acyl derivative of an amino acid ester where $n$ denotes the alkyl chain length

Alternatively, to find a substitute to cetrimonium bromide via CAMD (Task 4B) using the building blocks of amino acids, GC models for all the properties listed in Table 8, are required. The 'property model library' has been extended to include the GC models for the prediction of three physicochemical properties (normal melting point, $T_{m}$, aqueous water solubility, $W_{s}$, octanol water partition coefficient, $K_{o w}$ ) for 'amino acids and their derivatives' using the Marrero and Gani group contribution method (Jhamb, et al., 2018). However, the GC models for EH\&S properties (IC 50 and Biodegradation Rate) and the surface-active properties (Critical Micelle Concentration, CMC and Surface Tension at $\mathrm{CMC}, \sigma_{C M C}$ ) for these compounds are not yet available.

Therefore, the methodology identifies only two amino-acid based surfactants namely $\mathrm{N}_{\alpha}$-acylarginine methyl ester, $n=8$ and $\mathrm{N}_{\varepsilon}$-acyl lysine methyl ester, $n=10$ as potential substitutes to cetrimonium bromide. The evaluation of other EH\&S properties of the substitute candidates (Task 5) has not been performed due to unavailability of data for these properties. Also, the compatibility check using a rigorous property model has not been performed (Task 6) due to unavailability of a relevant model in the 'Property Model Library'. 
Lastly, it is to be noted that amino-acid based surfactants are more expensive than cetrimonium bromide due to the high cost of raw materials including fatty acids and amino acids ${ }^{54}$. But the benefits offered by these naturally derived surfactants is likely to compensate the high price (Task 7).

\section{1,2,4-Trichlorobenzene used in a Polymer-Spinning Process}

Ultra-High Molecular Weight - Polyethylene (UHMW-PE) can yield fibers with high mechanical strength after extrusion in a gel-spinning process. However, due to its high melt viscosity it cannot be directly extruded through a mechanical press. It is required to be dissolved in a solvent before it passes through the extruder and is spun into fibers. 1,2,4-trichlorobenzene is commonly used as a solvent for the dissolution of this polymer ${ }^{55}$. In a post-extrusion step, an extraction solvent, $n$-hexane is used to remove the solvent (1,2,4-trichlorobenzene) from the polymer gel fibers. However, 1,2,4trichlorobenzene appears on the REACH 'Restricted Substances List' and it therefore needs to be replaced by another environmentally benign, acceptable solvent.

The negative logarithm of $L C_{50}\left(-\log \left(L C_{50, F M}\right)\right)$ measured for fathead minnow $(\mathrm{FM})-\mathrm{a}$ freshwater fish is 4.7 for this solvent while its bioconcentration factor $(B C F)$ and degradation half-life in soil $\left(t_{1 / 2, \text { soil }}\right)$ is 1122 and 194 days respectively. According to the 'EH\&S Property Criteria Guide' a compound having $-\log \left(L C_{50, F M}\right)$ value greater than 3.5 is considered toxic to the aquatic environment. Besides, the logarithm value $B C F$ and $t_{1 / 2 \text { soil }}$ meet the EH\&S property criteria for substitution. Consequently, the objective to substitute 1,2,4-trichlorobenzene is its toxicity to the aquatic environment, bioaccumulation and persistence in the environment (soil) (Task 1). With the desired and undesired needs identified, they are converted to target pure component and mixture properties (Task 2) and the constraints are set on them (Task 3) as given in Table 10.

To find a substitute for 1,2,4-trichlorobenzene, firstly a database search is conducted (Task 4A). Decalin, which is a carbocyclic compound with two rings, has satisfactory physicochemical and functional properties for the process considered here $e^{56}$ and is commonly used in the gel spinning 
process. However, like 1,2,4-tricholorobenzene, this is also toxic to the aquatic environment (with $\left.\log \left(L C_{50, F M}\right) 4.8\right)$ besides being highly volatile. Apart from decalin, aromatic compounds like naphthalene ${ }^{57}$ and p-xylene ${ }^{58}$ are the other solvents currently used in this process but do not have satisfactory EH\&S properties.

Therefore, since the GC models for the prediction of the pure component properties are available in the property model library, CAMD is used to generate the compounds satisfying the target property constraints (Task 4B). Here, the molecular building blocks of carbocyclic compounds are chosen because these are similar to the repeating unit of the polymer to be dissolved. The building blocks of aromatic compounds are not used in order to avoid hazardous properties associated with these structures. Four compounds are found to satisfy the pure component physicochemical target properties. Out of these only methyl cycloundecane, satisfies the EH\&S property constraints.

Table 10. Needs, Target Properties and Constraints for 1,2,4-Trichlorobenzene Substitution

\begin{tabular}{|c|c|c|}
\hline Need & Target Property & Target Property Constraints \\
\hline \multicolumn{3}{|c|}{ Pure component, physicochemical and functional properties of substitute } \\
\hline $\begin{array}{l}\text { Ability to dissolve UHMW-PE at } \\
\text { operating temperature }\end{array}$ & Solubility Parameter $\left(\delta_{H i l d, 403 K}\right)$ & $16 \mathrm{MPa}^{1 / 2}<\delta_{H i l d, 403 K}<18 \mathrm{MPa}^{1 / 2}$ \\
\hline Low volatility & Vapor Pressure $\left(V P_{298 K}\right)$ & 0.0003 bar $<V P_{298 K}<0.0012$ bar \\
\hline Not too viscous to allow flowability & $\begin{array}{l}\text { Viscosity }(\eta) \\
\text { Density }(\rho)\end{array}$ & $\begin{array}{l}\eta<1.65 \mathrm{cP} \\
\rho<1.5{\mathrm{~g} . \mathrm{cm}^{-3}}^{-3}\end{array}$ \\
\hline $\begin{array}{l}\text { Liquid phase at operating } \\
\text { temperature }\end{array}$ & $\begin{array}{l}\text { Normal Melting Point }(N M P) \text {, } \\
\text { Normal Boiling point }(N B P)\end{array}$ & $\begin{array}{l}N M P<293.2 \mathrm{~K} \\
475.2 \mathrm{~K}<\mathrm{NBP}<600 \mathrm{~K}\end{array}$ \\
\hline \multicolumn{3}{|c|}{ Pure component, EH\&S properties of substitute } \\
\hline Non-toxic to aquatic environment & Lethal Concentration $\left(L C_{50, F M}\right)$ & $-\log L C_{50, F M}<3.5 \log \left(\right.$ mol. $\left.^{-1}\right)$ \\
\hline Does not bioaccumulate & Bioconcentration Factor $(B C F)$ & $\log B C F<3$ \\
\hline Does not persist in the atmosphere & Atmospheric Half Life ( $t_{1 / 2, \text { atmosphere })}$ & $t_{1 / 2, \text { soil }}<1120$ days \\
\hline \multicolumn{3}{|c|}{ Mixture properties to check compatibility with other chemicals in process } \\
\hline $\begin{array}{l}\text { Total Miscibility with the extraction } \\
\text { solvent (n-hexane) }\end{array}$ & Gibbs Energy of Mixing $\left(\Delta G_{m i x}\right)$ & $\Delta G_{m i x} / R T<0$ \\
\hline
\end{tabular}

Since, the average absolute error in the $-\log \left(L C_{50, F M}\right)$ and $\log (B C F)$ property prediction models is $0.48^{32}$ and $0.47^{32}$ respectively, these properties need to be verified using the property database containing experimental values for the EH\&S properties (Task 5). 
Lastly, it is required that the generated candidate is compatible with all other chemicals used in the original process (Task 6). This is checked using appropriate mixture property models. Since, the extraction solvent used to remove 1,2,4-Trichlorobenzene from the extruded polymer is $n$ hexane, the miscibility of the recognized substitute solvent with $n$-hexane is checked by calculating the Gibbs energy of mixing using Eq. (2).

$$
\frac{\Delta G_{m i x}}{R T}=\sum_{i}^{N C} x_{i} \ln \left(x_{i}\right)+\sum_{i}^{N C} x_{i} \ln \left(\gamma_{i}\right)<0
$$

Here, the activity coefficient $\left(\gamma_{i}\right)$ is estimated using the original UNIFAC model. The Gibbs energy of mixing $\left(\Delta G_{m i x}\right)$ at $298.2 \mathrm{~K}$ is found to be negative for all molar compositions of the methyl cycloundecane and $n$-hexane mixture (Figure 5), suggesting total miscibility.

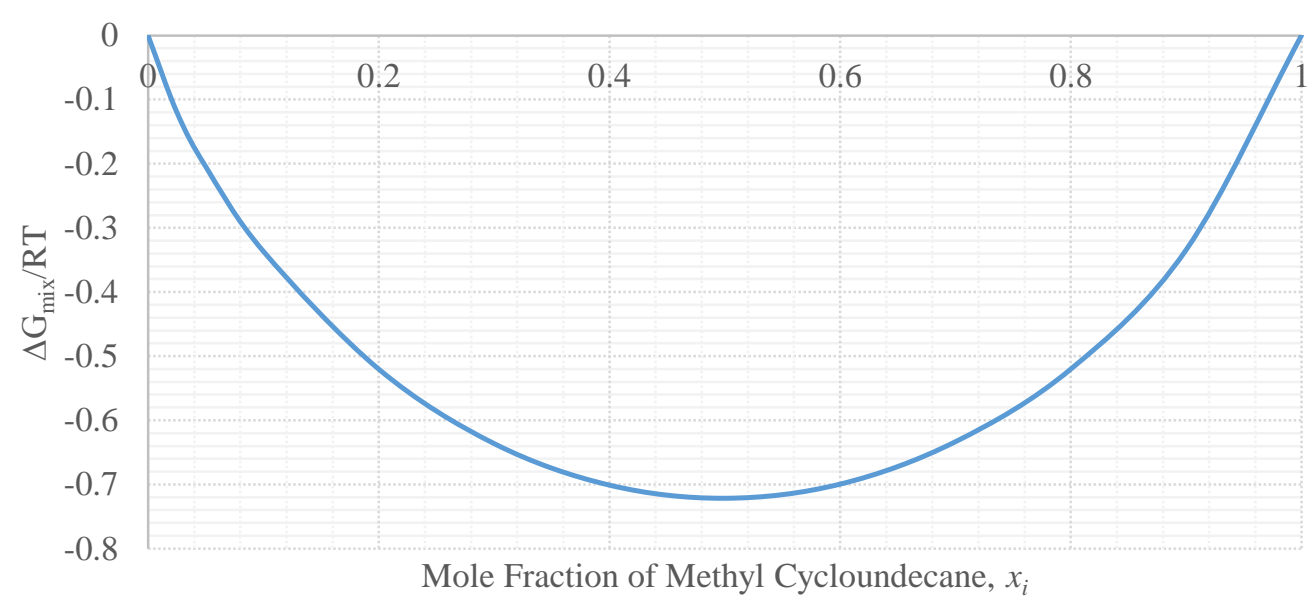

Figure 5: Gibbs energy of mixing for methyl cycloundecane- $n$-hexane mixture

Besides this, when the trend in the activity of methyl cycloundecane with increasing weight fraction in its mixture with UHMW-PE is checked, by using the UNIFAC-FV activity coefficient model $^{59}$, it is seen that the activity monotonically increases (Figure 6). This ensures the solubility of the polymer in methyl cycloundecane. 


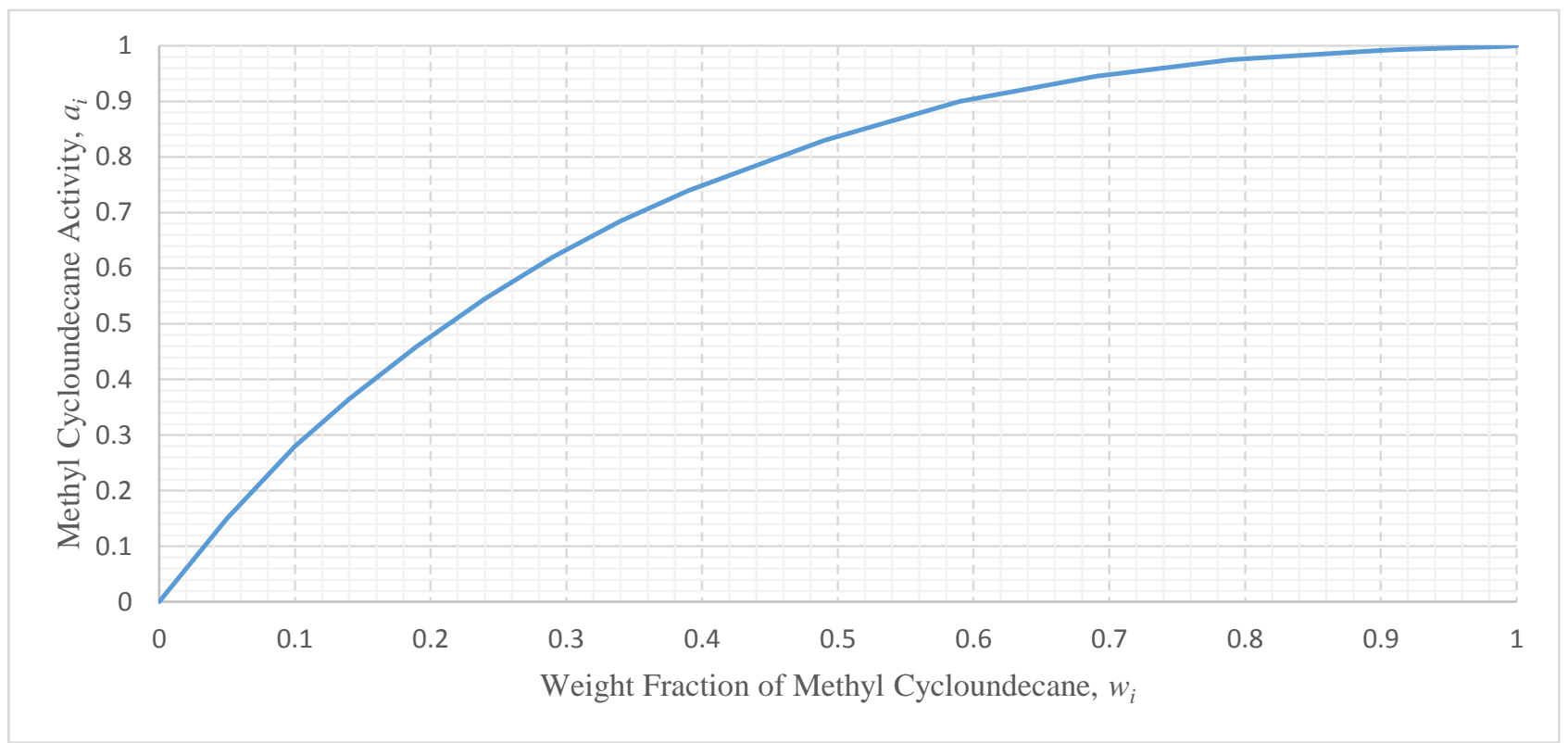

Figure 6. Methyl cycloundecane activity in methyl cycloundecane-polymer mixture using the UNIFAC-FV model

Therefore, methyl cycloundecane has comparable physicochemical and performance properties to 1,2,4-tricholrobenzene. This compound also does not bioaccumulate, degrades quickly in the soil and is non-toxic to the aquatic environment (Table 11). 
Table 11. Comparison of all properties of the viable substitute with 1,2,4-tricholorobenzene

\begin{tabular}{|c|c|c|c|c|c|c|c|c|c|c|c|c|}
\hline & Compound & $\begin{array}{l}\delta_{\text {Hild,298 K }} \\
\left(\mathrm{MPa}^{1 / 2}\right)\end{array}$ & $\begin{array}{l}F P \\
(\mathbf{K})\end{array}$ & $\begin{array}{c}N M P \\
(\mathbf{K})\end{array}$ & $\begin{array}{c}N B P \\
(\mathbf{K})\end{array}$ & $\begin{array}{c}V P \text { at } \\
298 \text { K (bar) }\end{array}$ & $\begin{array}{c}\rho \text { at } \\
293.2 \mathrm{~K} \\
(\mathrm{~g} / \mathrm{cc})\end{array}$ & \begin{tabular}{|c|}
$\eta$ at \\
305 K \\
(cP)
\end{tabular} & $\begin{array}{c}-\log \left(L C_{50, F M}\right) \\
\left(\log \mathrm{mol} \mathrm{L}^{-1}\right)\end{array}$ & $\log (B C F)$ & $\begin{array}{c}t_{1 / 2 \text {,soil }} \\
\text { (days) }\end{array}$ & $\begin{array}{c}\text { Miscibility with } \\
n \text {-hexane }\end{array}$ \\
\hline $\begin{array}{l}\text { Original } \\
\text { Compound }\end{array}$ & 1,2,4-tricholorobenzene & 20.32 & 378.2 & 290 & 486 & 0.00061 & 1.45 & 1.65 & 4.80 & 3.05 & 194 & Miscible \\
\hline $\begin{array}{l}\text { Viable } \\
\text { Substitute }\end{array}$ & Methyl cycloundecane & 16.60 & 341.6 & 236.5 & 484.7 & 0.00043 & 0.81 & 1.20 & 3.40 & 2.72 & 43 & Miscible \\
\hline
\end{tabular}


In order to define the range of applicability of the developed methodology, the successfully solved chemical substitution case-studies are categorized based on class of chemical product ${ }^{60}$ that contains the 'compound of concern'. These case-studies mainly belong to single molecular products and single/two-phase liquid formulated products category and are used as process solvents, operating fluids or complex consumer products (Figure 7).

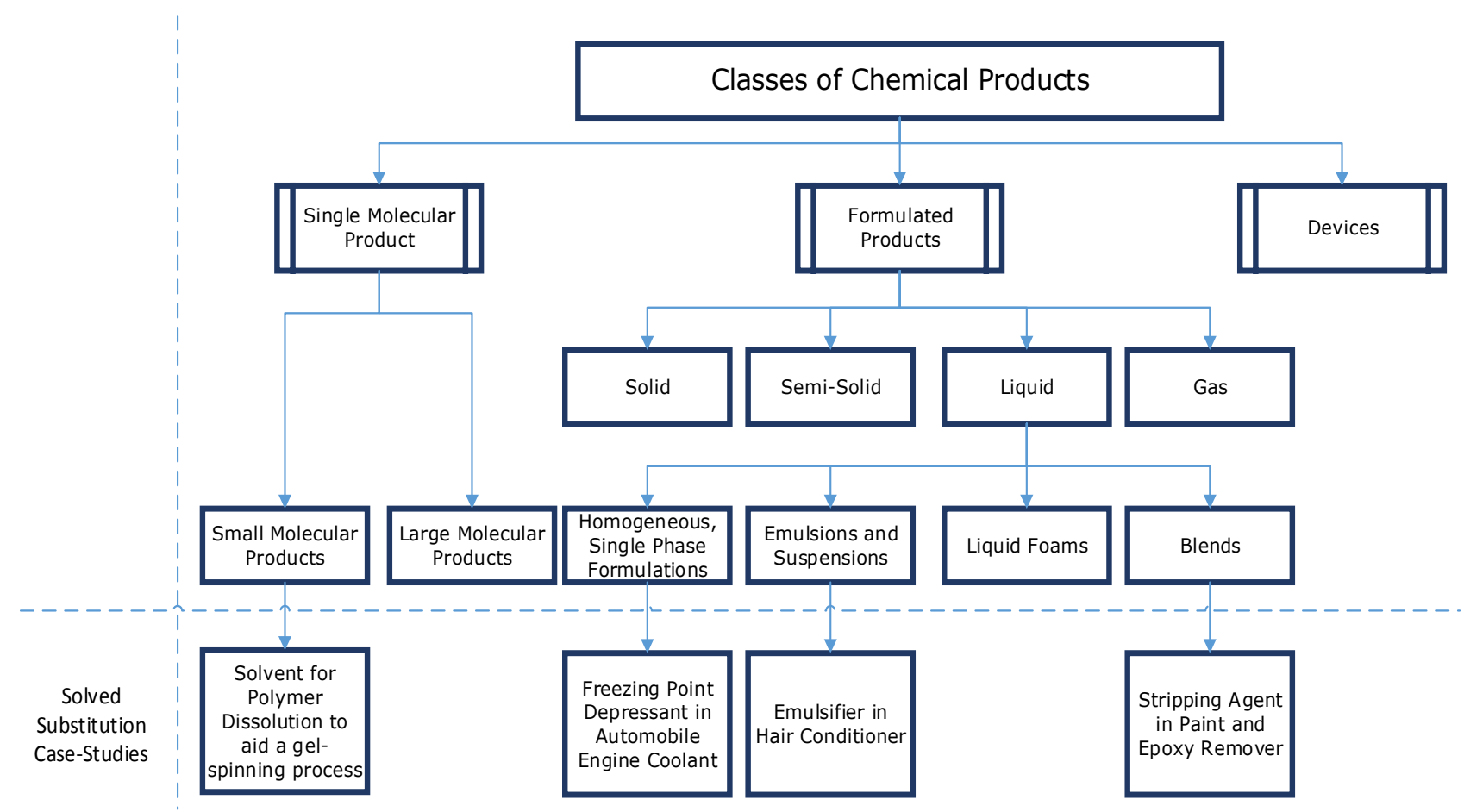

Figure 7. Class of chemical products for various substitution problems

\section{Conclusion}

A systematic model-based methodology for substituting chemicals from consumer products with a liquid delivery system or from processes and their operations, is developed. In addition to the traditional database search of alternative chemicals, the constraints on the desired, physicochemical and functional properties and the undesired EH\&S properties of the 'compound of concern' can be simultaneously used to generate substitute candidates via 'Computer-aided Molecular Design' from a set of given molecular building blocks without manual intervention. These are then checked for the 
product or process compatibility, economic feasibility and any other undesired EH\&S properties. Such an approach is advantageous as a potentially promising substitute candidate is not missed in the case when the needed data is not available and hence a reliable set of potential substitutes are quickly reached. For the final selection of the substitute compound the experimental efforts are focused only on these reliable candidates.

In practice, however, the scope of using CAMD is limited by the availability, reliability and accuracy of the models employed to predict the target properties. Due to the lack of availability of property prediction models for inorganic compounds in the model library, the computer-aided tool with the implemented methodology cannot currently recognize these compounds as substitute candidates. Consequently, the application of the substitution methodology is only limited to organic chemicals. Additionally, the application range of the methodology depends on the application range of the property models. The application range is constantly being expanded by developing and incorporating new models. Once, the required model parameters are estimated and the accuracy, ease of use, predictive capabilities of a developed model is evaluated, it can be easily added to the 'Property Model Library'.

Current and future work consists of tackling the substitution of chemicals in other types of consumeroriented chemical-based products, for instance, pharmaceutical products (tablets, inhalers, etc), cosmetic products (creams, powders, lotions) and food products (pastes, granules) that are very important and have wide applications in modern society. Identification and then substitution of any likely harmful chemicals from these products will advance this technology significantly. But this will also be more challenging than formulations with a liquid delivery system, since care must be taken such that, the introduction of the alternative chemical does not change the lattice structure (e.g. crystalline structure for powders and granules), which in-turn influences the properties like biological activity, friction, adhesion etc. and thermodynamic stability. 


\title{
SUPPORTING INFORMATION
}

I. Key scientific methods used in the development of the methodology

II. Results from Task 5 for the Case Studies applying the Developed Methodology

\section{AUTHOR INFORMATION}

\section{Corresponding Author}

Georgios M. Kontogeorgis. Phone: +45 452528 59, e-mail: gk@kt.dtu.dk.

\section{Notes}

The authors declare no competing financial interest.

\section{ACKNOWLEDGEMENT}

Financial support from Financial support from DTU Chemical Engineering and the Hempel Foundation to CoaST (The Hempel Foundation Coatings Science and Technology Centre).

\begin{abstract}
ABBREVIATIONS
$B C F$ : Bioconcentration Factor; $B O D_{5}$ : Biochemical Oxygen Demand for 5 days; CMR: Carcinogenic, Mutagenic, Reprotoxic; $C$ : Guidance value provided by Globally Harmonized System of Classification and Labelling of Chemicals (GHS); COD: Chemical Oxygen Demand; EATS: Estrogen, androgen, thyroid, steroidogenic; $E C_{50}$ : Median Effective Concentration resulting in immobilization of 50\% Daphnia magna population; $E_{5} C_{50}$ : Median Effective Concentration resulting in 50\% reduction of Algae Growth Rate; GWP: Global Warming Potential; $I_{50}$ : $50 \%$ Immobilization Concentration; $\mathrm{K}_{\mathrm{ow}}$ : Octanol-Water Partition Coefficient; $L C_{50}: 50 \%$ Lethal Concentration; $L D_{50}$ : 50\% Lethal Dose; ODP: Ozone Depletion Potential; OSHA - PEL: Occupational Safety and Health Administration - Permissible Exposure Limit; $t_{1 / 2}$ : (Biodegradation) Half - life; TWA: TimeWeighted Average
\end{abstract}




\section{REFERENCES}

(1) National Research Council. Reduce the Adverse Impacts of Chemicals in the Environment. In Linking Science and Technology to Society's Environmental Goals; National Academies Press: Washington, DC, 1996; pp 7-9, DOI 10.17226/5409.

(2) Malaj, E.; von der Ohe, P. C.; Grote, M.; Kühne, R.; Mondy, C. P.; Usseglio-Polatera, P.; Brack, W.; Schäfer, R. B. Organic Chemicals Jeopardize the Health of Freshwater Ecosystems on the Continental Scale. Proc. Natl. Acad. Sci. U. S. A. 2014, 111 (26), 9549-9554, DOI 10.1073/pnas.1321082111.

(3) European Commission. The Restriction of Hazardous Substances Directive http://ec.europa.eu/environment/waste/rohs_eee/index_en.htm (accessed Jan 10, 2019).

(4) European Agency for Safety and Health at Work (EU-OSHA). EU Directives http://osha.europa.eu/en/safetyand-health-legislation/european-directives (accessed Jan 10, 2019).

(5) Occupational Safety and Health Administration. Transitioning to Safer Chemicals http://www.osha.gov/dsg/safer_chemicals/why_transition.html (accessed Jan 10, 2019).

(6) Organization for Economic Cooperation and Development (OECD). Substitution Toolbox http://www.oecdsaatoolbox.org/ (accessed Jan 10, 2019).

(7) U.S. Environmental Protection Agency (EPA). Program for Assisting the Replacement of Industrial Solvents (PARIS III) http://www.epa.gov/chemical-research/program-assisting-replacement-industrial-solvents-paris-iii (accessed Jan 10, 2019).

(8) U.S. National Library of Science. Hazardous Substances Data Bank (HSDB) http://toxnet.nlm.nih.gov/newtoxnet/hsdb.htm (accessed Jan 10, 2019).

(9) International Chemical Secretariat (ChemSec). SIN List http://chemsec.org/sin-list/ (accessed Jan 10, 2019).

(10) International Chemical Secretariat (ChemSec). SINimilarity http://chemsec.org/business-tool/sinimilarity/ (accessed Jan 10, 2019).

(11) Holder, H.A; Mazurkiewicz, P. H.; Robertson, C. D.; Wray, C. A. Hewlett-Packard's Use of the GreenScreen ${ }^{\mathrm{TM}}$ for Safer Chemicals. In Chemical Alternatives Assessments; Hester, R. E.; Harrison, R. M., Ed.; Royal Society of Chemistry: Cambridge, U.K., 2013; pp 157-176, DOI 10.1039/9781849737234

(12) Organization for Economic Cooperation and Development (OECD). Nonylphenol Ethoxylates (NPEs) in AllPurpose Cleaners Case-Study Details http://www.oecdsaatoolbox.org/Home/CaseStudiesDetails?ID=3 (accessed Feb 10, 2019).

(13) U.S. Environmental Protection Agency (EPA). Ecotoxicology Database http://www.epa.gov/chemicalresearch/ecotoxicology-database (accessed Jan 10, 2019).

(14) ChemSpider Home Page http://www.chemspider.com (accessed Jan 10, 2019).

(15) GreenBlue. CleanGredients: The Online Resource for Green Formulation http://greenblue.org/work/cleangredients (accessed Jan 10, 2019).

(16) U.S. Environmental Protection Agency (EPA). Safer Chemical Ingredients List http://www.epa.gov/saferchoice/safer-ingredients (accessed Jan 10, 2019).

(17) Occupational Safety and Health Administration (OSHA). OSHA Occupational Chemical Database http://www.osha.gov/chemicaldata (accessed Jan 10, 2019).

(18) Swedish Chemical Inspectorate (KemI). PRIO: A Tool For Risk Reduction and Analysis http://www.kemi.se/en/prio-start (accessed Jan 10, 2019).

(19) Clean Production Action. GreenScreen ${ }^{\circledR}$ For Safer Chemicals http://www.greenscreenchemicals.org (accessed Jan 10, 2019).

(20) Toxics Use Reduction Institute (TURI). Pollution Prevention Options Analysis System (P2OASys): Tool to 
http://www.turi.org/Our_Work/Research/Alternatives_Assessment/Tools_and_Methods/P2OASys_Tool_to_Co mpare_Materials (accessed Jan 10, 2019).

(21) U.S. Environmental Protection Agency (EPA). OncoLogic ${ }^{\mathrm{TM}}$ - A Computer System to Evaluate the Carcinogenic Potential of Chemicals http://www.epa.gov/tsca-screening-tools/oncologictm-computer-system-evaluatecarcinogenic-potential-chemicals (accessed Jan 10, 2019).

(22) The Umweltbundesamt. SubSelect - Guide for the Selection of Sustainable Chemicals http://www.umweltbundesamt.de/en/document/subselect-guide-for-the-selection-of-sustainable (accessed Jan 10, 2019).

(23) European Chemical Agency (EChA). Substances of Very High Concern Identification http://echa.europa.eu/fr/substances-of-very-high-concern-identification-explained (accessed Jan 10, 2019).

(24) U.S. Environmental Protection Agency (EPA). Design for the Environment Programs, Initiatives, and Projects http://www.epa.gov/saferchoice/design-environment-programs-initiatives-and-projects (accessed Jan 10, 2019).

(25) National Research Council. The Committee's Framework. In A Framework to Guide Selection of Chemical Alternatives; National Academies Press: Washington, DC, 2014; pp 23-34, DOI 10.17226/18872.

(26) Sweetlove, C.; Chenèble, J. C.; Barthel, Y.; Boualam, M.; L’Haridon, J.; Thouand, G. Evaluating the Ready Biodegradability of Two Poorly Water-Soluble Substances: Comparative Approach of Bioavailability Improvement Methods (BIMs). Environ. Sci. Pollut. Res. 2016, 23 (17), 17592-17602, DOI 10.1007/s11356016-6899-3.

(27) Gani, R.; Nielsen, B.; Fredenslund, A. A Group Contribution Approach to Computer-Aided Molecular Design. AIChE J. 1991, 37 (9), 1318-1332, DOI 10.1002/aic.690370905.

(28) Fisk, P. Substance Classification and Labelling under REACH. In Chemical Risk Assessment: A Manual for REACH; John Wiley \& Sons, Ltd: Bognor Regis, U.K., 2013; pp 317-339, DOI 10.1002/9781118683989.

(29) Marrero, J.; Gani, R. Group-Contribution Based Estimation of Pure Component Properties. Fluid Phase Equilib. 2001, 183-184, 183-208, DOI 10.1016/S0378-3812(01)00431-9.

(30) Cunico, L. P.; Hukkerikar, A. S.; Ceriani, R.; Sarup, B.; Gani, R. Molecular Structure-Based Methods of Property Prediction in Application to Lipids: A Review and Refinement. Fluid Phase Equilib. 2013, 357 (15), 2-18, DOI 10.1016/j.fluid.2013.04.004.

(31) Jhamb, S.; Liang, X.; Gani, R.; Hukkerikar, A. S. Estimation of Physical Properties of Amino Acids by GroupContribution Method. Chem. Eng. Sci. 2018, 175, 148-161, DOI 10.1016/j.ces.2017.09.019.

(32) Hukkerikar, A. S.; Kalakul, S.; Sarup, B.; Young, D. M.; Sin, G.; Gani, R. Estimation of Environment-Related Properties of Chemicals for Design of Sustainable Processes: Development of Group-Contribution+ $(\mathrm{GC}+)$ Property Models and Uncertainty Analysis. J. Chem. Inf. Model. 2012, 52 (11), 2823-2839, DOI $10.1021 / \mathrm{ci} 300350 \mathrm{r}$.

(33) Marrero, J.; Gani, R. Chapter 3: Pure Component Property Estimation: Models \& Databases. In Computer Aided Property Estimation for Process and Product Design; Kontogeorgis, G.M.; Gani, R., Ed.; 2004; pp 45-57, DOI 10.1016/S1570-7946(04)80005-1.

(34) Yunus, N. A. B.; Gernaey, K. V.; Woodley, J. M.; Gani, R. A Systematic Methodology for Design of TailorMade Blended Products. Comput. Chem. Eng. 2014, 66, 201-213, DOI 10.1016/j.compchemeng.2013.12.011.

(35) Zhang, L.; Kalakul, S.; Liu, L.; Elbashir, N. O.; Du, J.; Gani, R. A Computer-Aided Methodology for MixtureBlend Design. Applications to Tailor-Made Design of Surrogate Fuels. Ind. Eng. Chem. Res. 2018, 57 (20), 7008 7020, DOI 10.1021/acs.iecr.8b00775.

(36) Conte, E.; Gani, R.; Ng, K. M. Design of Formulated Products: A Systematic Methodology. AIChE J. 2011, 57 (9), 2431-2449, DOI 10.1002/aic.12458.

(37) Mattei, M.; Kontogeorgis, G. M.; Gani, R. A Systematic Methodology for Design of Emulsion Based Chemical Products. Comput. Aided Chem. Eng. 2012, 31, 220-224, DOI 10.1016/B978-0-444-59507-2.50036-6. 
(38) Muro-Suñé, N.; Gani, R.; Bell, G.; Shirley, I. Model-Based Computer-Aided Design for Controlled Release of Pesticides. Comput. Chem. Eng. 2005, 30 (1), 28-41, DOI 10.1016/j.compchemeng.2005.07.001.

(39) Gani, R.; Hytoft, G.; Jaksland, C.; Jensen, A. K. An Integrated Computer Aided System for Integrated Design of Chemical Processes. Comput. Chem. Eng. 1997, 21 (10), 1135-1146, DOI 10.1016/S0098-1354(96)00324-9.

(40) Kalakul, S.; Zhang, L.; Fang, Z.; Choudhury, H. A.; Intikhab, S.; Elbashir, N.; Eden, M. R.; Gani, R. Computer Aided Chemical Product Design - ProCAPD and Tailor-Made Blended Products. Comput. Chem. Eng. 2018, 116, 37-55, DOI 10.1016/j.compchemeng.2018.03.029.

(41) Consumer Products Information Database Home Page http://www.whatsinproducts.com (accessed Jan 10, 2019).

(42) Agency for Toxic Substances and Disease Registry of U.S. Department for Health and Human Services. Toxicological Profile for Ethylene Glycol http://www.atsdr.cdc.gov/ToxProfiles/tp.asp?id=86\&tid=21 (accessed Jan 10, 2019).

(43) Miljøstyrelsen Denmark. Organiske opløsningsmidler i $\quad$ husholdningsprodukter http://mst.dk/service/publikationer/publikationsarkiv/1988/jan/organiske-oploesningsmidler-ihusholdningsprodukter.

(44) Erickson, B. E. EPA to Ban Methylene Chloride in Paint Strippers. C\&EN Glob. Enterp. 2018, 96 (20), 16, DOI 10.1021/cen-09620-polcon5.

(45) Lovell, T. Walmart to Phase out Methylene Chloride and NMP Paint Strippers. Chemical Watch Global Risk and Regulation News. August 2018.

(46) Launay, H.; Hansen, C. M.; Almdal, K. Hansen Solubility Parameters for a Carbon Fiber/Epoxy Composite. Carbon N. Y. 2007, 45 (15), 2859-2865, DOI 10.1016/j.carbon.2007.10.011.

(47) Tukker, A., Simons, L. P. Methylene Cloride: Advantages and Drawbacks of Possible Market Restrictions in the EU; Technical Report; TNO; Brussels, Belgium, 1997.

(48) Independent Chemical Information Service (ICIS). Indicative Chemical Prices A-Z http://www.icis.com/explore/commodities/chemicals/channel-info-chemicals-a-z/ (accessed Jan 10, 2019).

(49) Cetyltrimethylammonium Bromide Safety Data Sheet Acc. to Regulation (EC) No. 1907/2006 (REACH); Carl Roth GmbH, Karlsruhe, Germany.

(50) U.S. Environmental Protection Agency (EPA). Safer Choice Criteria for Surfactants http://www.epa.gov/saferchoice/safer-choice-criteria-surfactants (accessed Jan 10, 2019).

(51) Organization for Economic Cooperation and Development (OECD). Test No. 301: Ready Biodegradability. In OECD Guidelines for Testing of Chemicals, Section 3; 2018, DOI 10.1787/9789264070349-en.

(52) Infante, M. R.; Pérez, L.; Pinazo, A.; Clapés, P.; Morán, M. C.; Angelet, M.; García, M. T.; Vinardell, M. P. Amino Acid-Based Surfactants. Comptes Rendus Chim. 2004, 7 (6-7), 583-592, DOI 10.1016/j.ijporl.2010.08.004.

(53) Pérez, L.; Garcia, M. T.; Ribosa, I.; Vinardell, M. P.; Manresa, A.; Infante, M. R. Biological Properties of Arginine-Based Gemini Cationic Surfactants. Environ. Toxicol. Chem. 2002, 21 (6), 1279-1285, DOI 10.1002/etc.5620210624.

(54) Wu, M.-H.; Wan, L.-Z.; Zhang, Y.-Q. A Novel Sodium N-Fatty Acyl Amino Acid Surfactant Using Silkworm Pupae as Stock Material. Sci. Rep. 2015, 4, 1-8, DOI 10.1038/srep04428.

(55) Fang, X.; Wyatt, T.; Hong, Y.; Yao, D. Gel Spinning of UHMWPE Fibers with Polybutene as a New Spin Solvent. Polym. Eng. Sci. 2016, 56 (6), 697-706, DOI 10.1002/pen.24296.

(56) Schaller, R.; Feldman, K.; Smith, P.; Tervoort, T. A. High-Performance Polyethylene Fibers "Al Dente": Improved Gel-Spinning of Ultrahigh Molecular Weight Polyethylene Using Vegetable Oils. Macromolecules 2015, 48 (24), 8877-8884, DOI 10.1021/acs.macromol.5b02211.

(57) Yasuda, H; Ban, K; Ohta, Y. Gel Spinning Process. In Advanced fiber spinning technology; Nakajima, T., Ed.; Woodhead Publishing Ltd.: Cambridge, U.K., 1994; pp 172-186. 
(58) Fang, L. M.; Gao, P.; Cao, X. W. Temperature Window Effect and Its Application in Extrusion of Ultrahigh Molecular Weight Polyethylene. Express Polym. Lett. 2011, 5 (8), 674-684, DOI 10.3144/expresspolymlett.2011.66.

(59) Oishi, T.; Prausnitz, J. M. Solvent Activities in Polymer Solutions Using a Group-Contribution Method. Ind. Eng. Chem. Process Des. Dev. 1978, 17 (3), 333-339, DOI 10.1021/i260067a021.

(60) Gani, R.; Ng, K. M. Product Design - Molecules, Devices, Functional Products, and Formulated Products. Comput. Chem. Eng. 2015, 81, 70-79, DOI 10.1016/j.compchemeng.2015.04.013.

\section{TOC / ABSTRACT GRAPHIC ART}

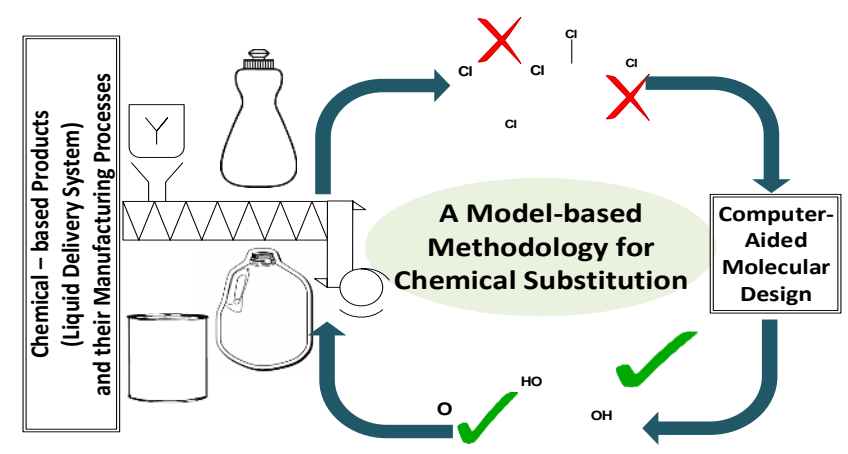

Synopsis: The paper presents a methodology to substitute chemicals, which are environmentally hazardous and unsafe to human health, but have an important function in chemical-based products and their manufacturing processes, by means of Computer-aided Molecular Design. 